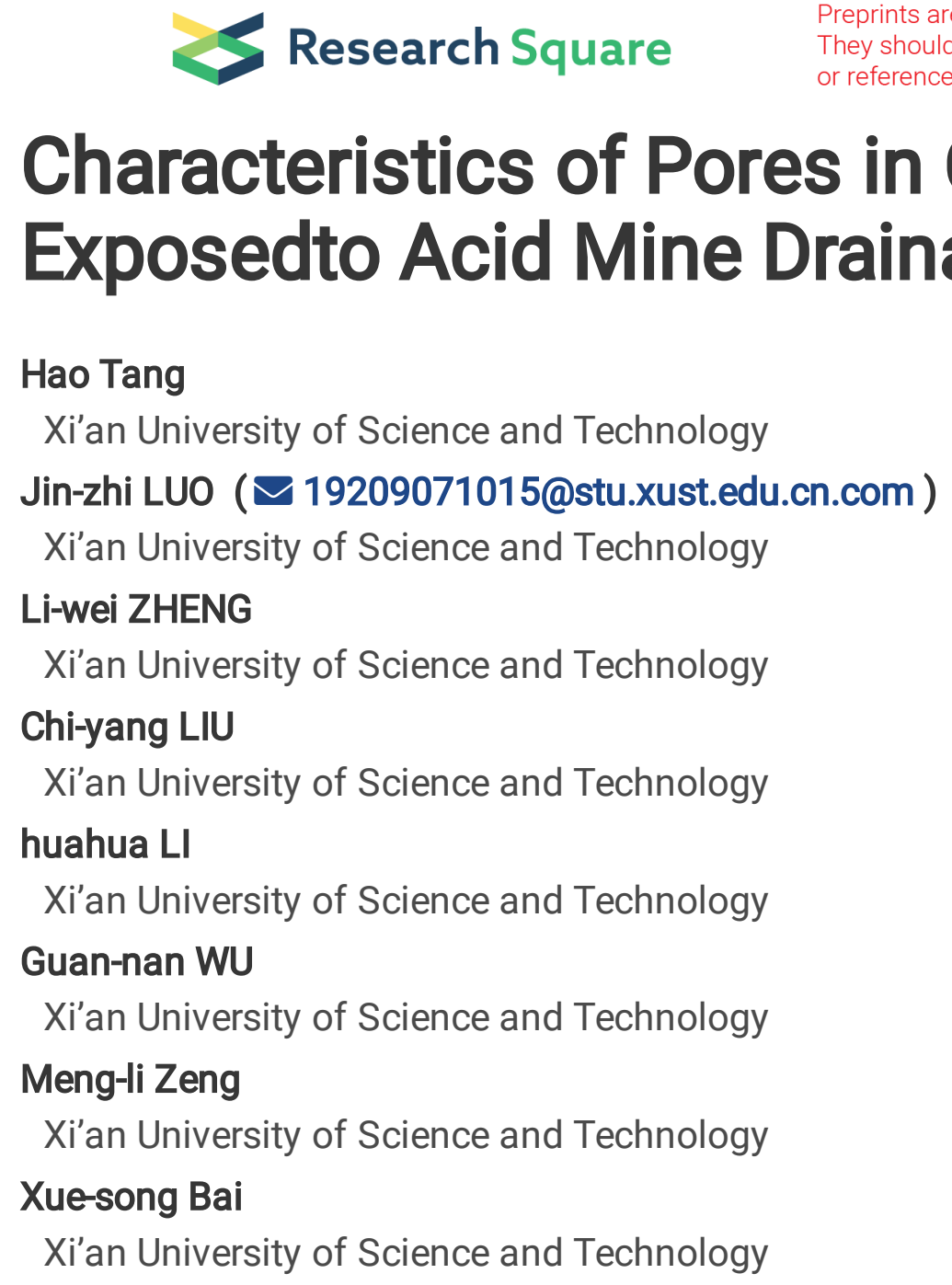

Hao Tang

Xi'an University of Science and Technology

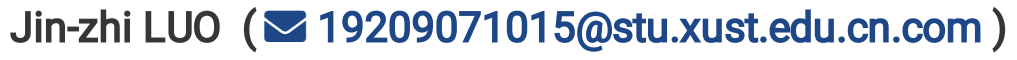

Xi'an University of Science and Technology

\section{Li-wei ZHENG}

Xi'an University of Science and Technology

\section{Chi-yang LIU}

Xi'an University of Science and Technology

huahua LI

Xi'an University of Science and Technology

\section{Guan-nan WU}

Xi'an University of Science and Technology

Meng-li Zeng

Xi'an University of Science and Technology

\section{Xue-song Bai}

Xi'an University of Science and Technology

\title{
Characteristics of Pores in Coals Samples Exposedto Acid Mine Drainage
}

\section{Research Article}

Keywords: acid mine drainage, chemical erosion, immersion test, pore orientation, pore size

Posted Date: June 1st, 2021

DOl: https://doi.org/10.21203/rs.3.rs-554654/v1

License: (c) (1) This work is licensed under a Creative Commons Attribution 4.0 International License. Read Full License 


\section{Characteristics of pores in coals samples exposedto acid mine drainage}

Author(s): Hao TANG ${ }^{1,2}$; Jin-zhi LUO ${ }^{1}$, Li-wei ZHENG ${ }^{1}$, Chi-yang LIU ${ }^{1}$, Hua-hua

$\mathrm{LI}^{1}$, Guan-nan $\mathrm{WU}^{1}$, Meng-li ZENG ${ }^{1}$, Xue-song BAI ${ }^{1}$

\section{Affiliation(s):}

${ }^{1}$ Ph.D., College of Geology and Environment, Xi'an University of Science and Technology, Xi'an, Shaanxi, 710054, China.

${ }^{2}$ Key Laboratory of Geological Support for Coal Green Exploitation, Xi'an, Shaanxi, 710054, China.

*Corresponding Author : Jin-zhi LUO, E-mail: 19209071015@stu.xust.edu.cn.com.

Type of submission: research article

Number of figures: 16

Number of tables: 3 
1 Abstract: Acid mine drainage commonly occupies some pore space after underground

2 coal mining, and this severely depreciates coal pillars, thereby posing a significant risk

3 to mine stability. Considering that such depreciation is reflected in the microstructures

4 of these pillars, in the present study, we propose a static immersion method suitable for

5 coal seam samples immersion in the laboratory. We immersed the No. 2-2 coal seam

6 samples from the Ningtiao Tower Coal Mine in Yulin, Shaanxi Province, in different

7 acid mine drainage solutions and monitored the $\mathrm{pH}$, oxidation-reduction potential

8 (ORP), electrical conductivity (EC), total dissolved solids (TDS) among other water

9 quality parameters for $300 \mathrm{~h}$. After the immersion tests, samples were examined using scanning electron microscopy (SEM). The $\mathrm{pH}, \mathrm{ORP}, \mathrm{EC}$, and TDS of the prepared acid

11 mine drainage solutions increased significantly as the immersion time increased. Changes in water quality parameters are attributed to the absorption of hydrogen ions by insoluble clay minerals in the coal, which reduced the acidity, increased the $\mathrm{pH}$ value, and enhanced the electrical conductivity of the acid mine drainage solutions. SEM analysis reveals differences in the pore characteristics of (pore throat size and orientation) of the coal samples, and these are caused by erosive effects of the acid mine drainage solutions. Pores with throat sizes greater than $10 \mu \mathrm{m}$ increased by $95 \%$ as the $\mathrm{pH}$ of the acid mine drainage solutions decreased, while the dominant pore orientation $\left(60-90^{\circ}\right)$ decreased to the $0-30^{\circ}$ or increased to the $150-180^{\circ}$ range, thereby increasing their randomness.

Keywords: acid mine drainage, chemical erosion, immersion test, pore orientation, pore size 


\section{Introduction}

Acid mine drainage in a coal mine, which refers to the discharge of acidic wastewater from current mining or mined coal seams, is a global concern ${ }^{1}$. It originates from hydrochemical reactions between sulfide minerals contained in coal seams and groundwater, during which hydrogen and heavy metal ions (e.g., manganese and iron) are released, thereby elevating the acidity of the groundwater ${ }^{2,3}$. This mining byproduct is a problem in countries, such as China ${ }^{4,5}$, the $\mathrm{USA}^{4,5}$, South Africa ${ }^{8,9}$, and Brazil ${ }^{10}$, where it is gradually impeding underground coal mining activities.

Acid mine drainage interacts with coal because of its complex composition ${ }^{11}$. In addition, because coal contains several minerals ${ }^{12}$, its physical and chemical properties change significantly after long immersion in water ${ }^{13-15}$. Dissolution of organic and inorganic components cause structural damage of the coal and enhances the dissolved ion content of the water ${ }^{15}$. The interaction between immersed coal and water accelerates its chemical damage16, which is manifested by increasing or decreasing oxygen-containing functional groups, such as the carboxy ${ }^{1}$ and hydroxyl $1^{17,18}$. Dissolved metal ions react with oxygen-containing functional groups in the immersed coal, thereby promoting the oxidation of some metal ions. This decreases the oxygen contents of these functional groups, and eventually, lowers the spontaneous combustion risk of the coal ${ }^{19}$.

Existing studies on the chemical effects of acidic water on coal involve soaking coal gangue in aqueous solutions of nitric or sulfuric acid to simulate a static or dynamic acidic water environment. Results show that metals precipitation depends on the host 
environment, and thus, because an acidic environment affects the metals in coal, their precipitation is also impacted. The ion precipitation potential increases as acidity of a solution increases ${ }^{3,20}$. The ion leaching process, which represents the coal - water interaction system, can be divided into the following stages: the calcite alkaline, silicate acidic, sulfide acidic, and the continuous reaction ${ }^{21}$. According to previous studies, this promotes enrichment in trace metals, thereby enhancing groundwater and soil pollution over time $e^{22}$.

However, previous studies focus on the precipitation of metals in coal caused by the water - rock interaction, the concentration of these metals in the environment, the pollution methods, and the effects of coal mining on groundwater and soil. In addition, these studies rely mostly on static immersion, and thus, the chemical erosion effects of chemical degradation of coal by acid mine drainage has received little attention. Consequently, the effects of acidic water (sulfuric or hydrochloric acid and their mixtures) on the precipitation of metals in coal and the alteration of its combustion characteristics are commonly discussed without considering chemical degradation caused by acid mine drainage. Further, coal microstructure is often investigated to assess changes in minerals such as silica, pyrite, and clay minerals as well as trace elements after acid immersion. Changes in the pore structure (pore throat size and pore orientation) $^{23,24}$ remain poorly studied.

Therefore, in the present study, we conducted static immersion experiments on coal samples immersed in simulated mine water of varying acidity levels ( $\mathrm{pH}$ of $2-5$ ), to evaluate their impact on water quality parameters $(\mathrm{pH}$, oxidation - reduction potential 
(ORP), electrical conductivity (EC), and total dissolved solids (TDS)) over time. We also examined the coal samples after the experiments using SEM to assess the pore size and orientation characteristics associated with various acidic environments. The findings of the present study improve understanding of the characteristics of pores in coal samples exposed to acid mine drainage.

\section{Materials and Methods}

\subsection{Coal properties and sample preparation process}

The coal used in the present study was obtained from a 2-2 coal seam in the Ningtiaota Coal Mine in Shenmu County, Yulin City, Shaanxi Province $\left(110^{\circ} 1713.48^{\prime \prime}\right.$ E, 39 $228.27^{\prime \prime} \mathrm{N}$ ) (Fig. 1). The coal seam is at depths ranging between 414.05 and $418.39 \mathrm{~m}$, with an average depth of $416.22 \mathrm{~m}$ and the thickness varies between 3.85 and $4.11 \mathrm{~m}$. Data for analysis of conventional coal parameters, such as moisture on dry air basis (Mad), ash on dry air basis (Aad), volatile fraction on a dry ash-free basis (Vdaf), total sulfur content on a dry basis (St.d), and dry gross calorific value (Qgr,d), are presented in Table 1. The coal sample size used for the immersion experiments measured $50 \mathrm{~mm}$ in diameter and $100 \mathrm{~mm}$ in height, following the International Society for Rock Mechanics (ISRM) standards. These cylindrical samples were obtained by wet drilling using a rock coring machine, and the sampling process is illustrated in Fig. 2. 


\begin{tabular}{|c|c|c|c|c|c|c|c|}
\hline \multirow[b]{2}{*}{ Mad (\%) } & \multirow[b]{2}{*}{ Aad (\%) } & \multirow[b]{2}{*}{ Vdaf $(\%)$} & \multirow[b]{2}{*}{ St.d (\%) } & \multirow[b]{2}{*}{ Qgr.d $(\mathrm{KJ} / \mathrm{g})$} & \multicolumn{3}{|c|}{ Mineral base (\%) } \\
\hline & & & & & clays & sulfides & carbonates \\
\hline 6.59 & 36.29 & 37.15 & 0.33 & 19.50 & $0-5.6$ & $0-0.4$ & $0-0.4$ \\
\hline
\end{tabular}

Figure 1. Sampling site of raw coal.

Table 1 Data for conventional parameters used for coal characterization.

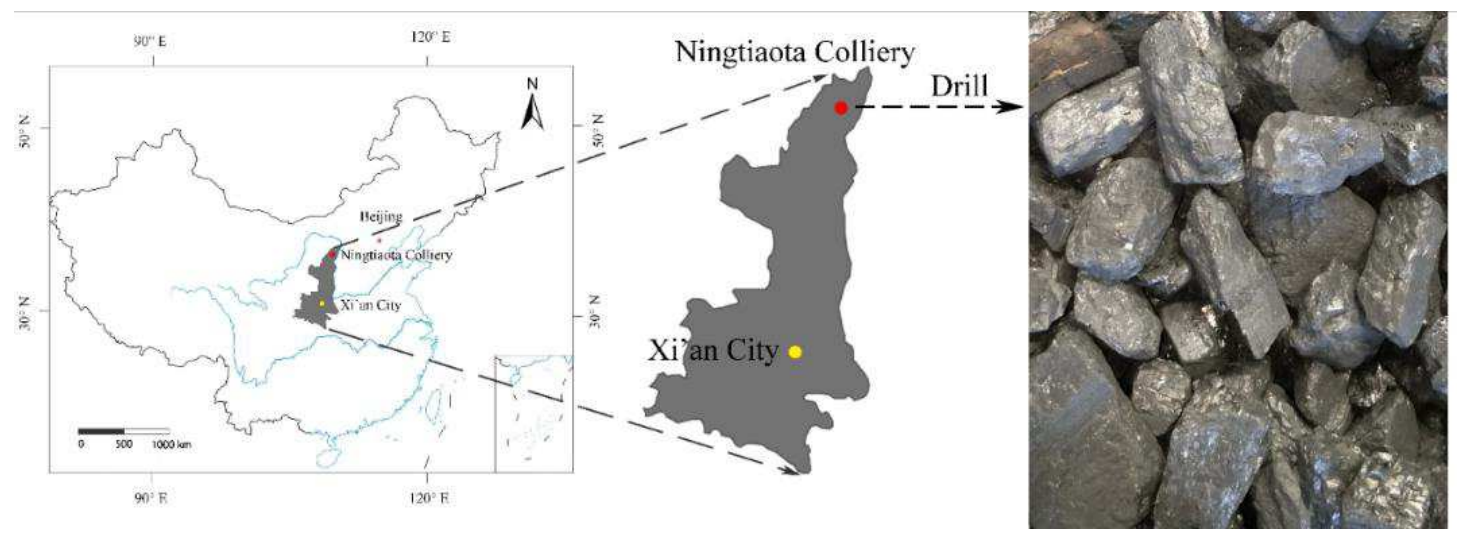



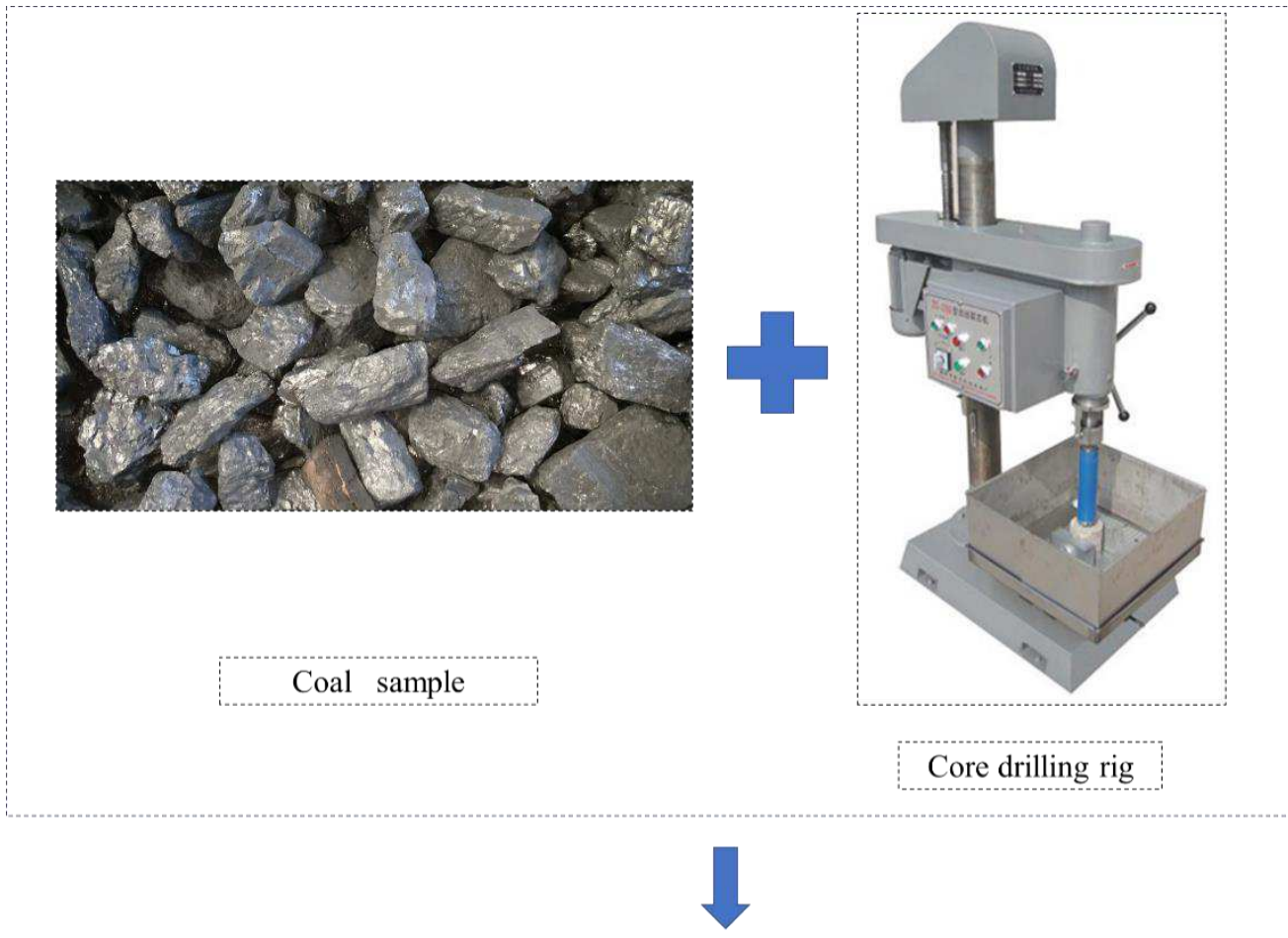

The drilled coal core is then cut and polished at both ends and leveled until the height is $100 \mathrm{~mm}$.

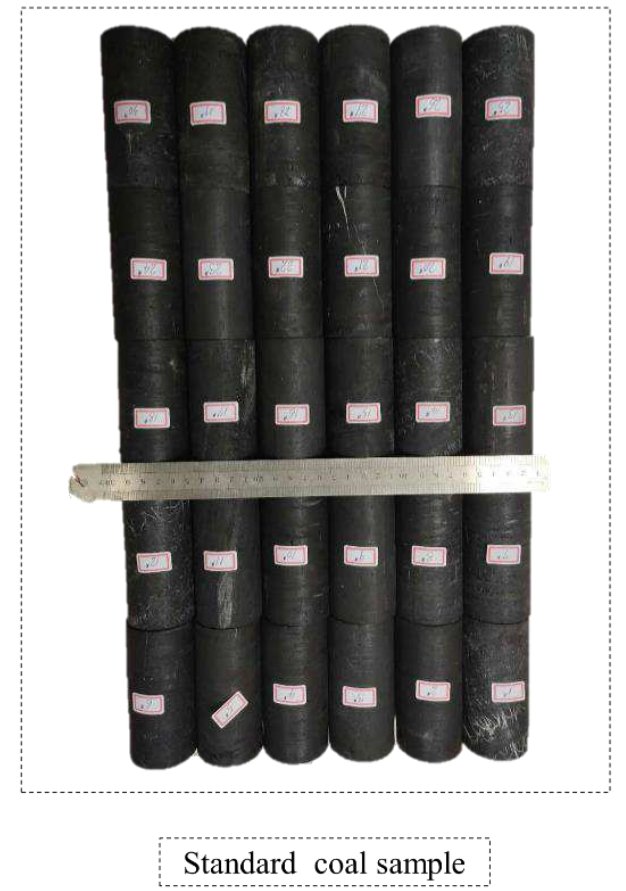

Figure 2 Illustration of the coal sample preparation processs.

\subsection{Preparation of the Hydrochemical solution}

According to previous studies ${ }^{25}$, acid mine drainage in the coal seam is enriched in ions, such as $\mathrm{Fe}^{2+}, \mathrm{Fe}^{3+}, \mathrm{Al}^{3+}, \mathrm{Mg}^{2+}, \mathrm{Ca}^{2+}, \mathrm{Mn}^{2+}, \mathrm{Cl}^{-}$, and $\mathrm{SO}_{4}{ }^{2-}$, which promote acidification. 
Therefore, we used sodium sulfate, magnesium chloride, ferrous sulfate, ferric chloride, and other salts to simulate acid mine drainage containing the main ions (initial $\mathrm{pH}=5$ ) in the mine. The proportions of salts used are presented in Table 2 and the simulated solutions were prepared using dilute hydrochloric acid $(\mathrm{pH}=2)$.

Table 2 Proportion of salts mixing employed for simulated acid mine drainage preparation.

\begin{tabular}{cccccccc}
\hline \multicolumn{7}{c}{ Chemicals (g/L) } \\
\hline $\mathrm{NH}_{4} \mathrm{Cl}$ & $\mathrm{K}_{2} \mathrm{HPO}_{3}$ & $\mathrm{Na}_{2} \mathrm{SO}_{4}$ & $\mathrm{MgSO}_{4} \cdot 7 \mathrm{H}_{2} \mathrm{O}$ & $\mathrm{CuCl}_{2} \cdot 2 \mathrm{H}_{2} \mathrm{O}$ & $\mathrm{ZnCl}_{2}$ & $\mathrm{FeSO}_{4} \cdot 7 \mathrm{H}_{2} \mathrm{O}$ & $\mathrm{MnNO}_{3}$ \\
& & & & & & & \\
0.191 & 0.075 & 2.215 & 3.844 & 0.0797 & 0.0628 & 0.149 & 0.169 \\
\hline
\end{tabular}

\subsection{Test scheme}

Acid mine drainage immersion coal tests were performed using solutions with $\mathrm{pH}$ values of 2, 3, 4, and 5 (Fig. 3). These solutions are henceforth denoted as $\mathrm{pH}-5$, $\mathrm{pH}-4$, $\mathrm{pH}-3$, and $\mathrm{pH}-2$, with these simply indicating the initial $\mathrm{pH}$ values, because the acidity values of the solutions were altered by the immersion of coal samples. Water quality parameters (pH, (ORP), (EC), and (TDS)) of each simulated solution was monitored throughout the coal samples recovered after the immersion tests were prepared and examined using a scanning electron microscope (SEM). 


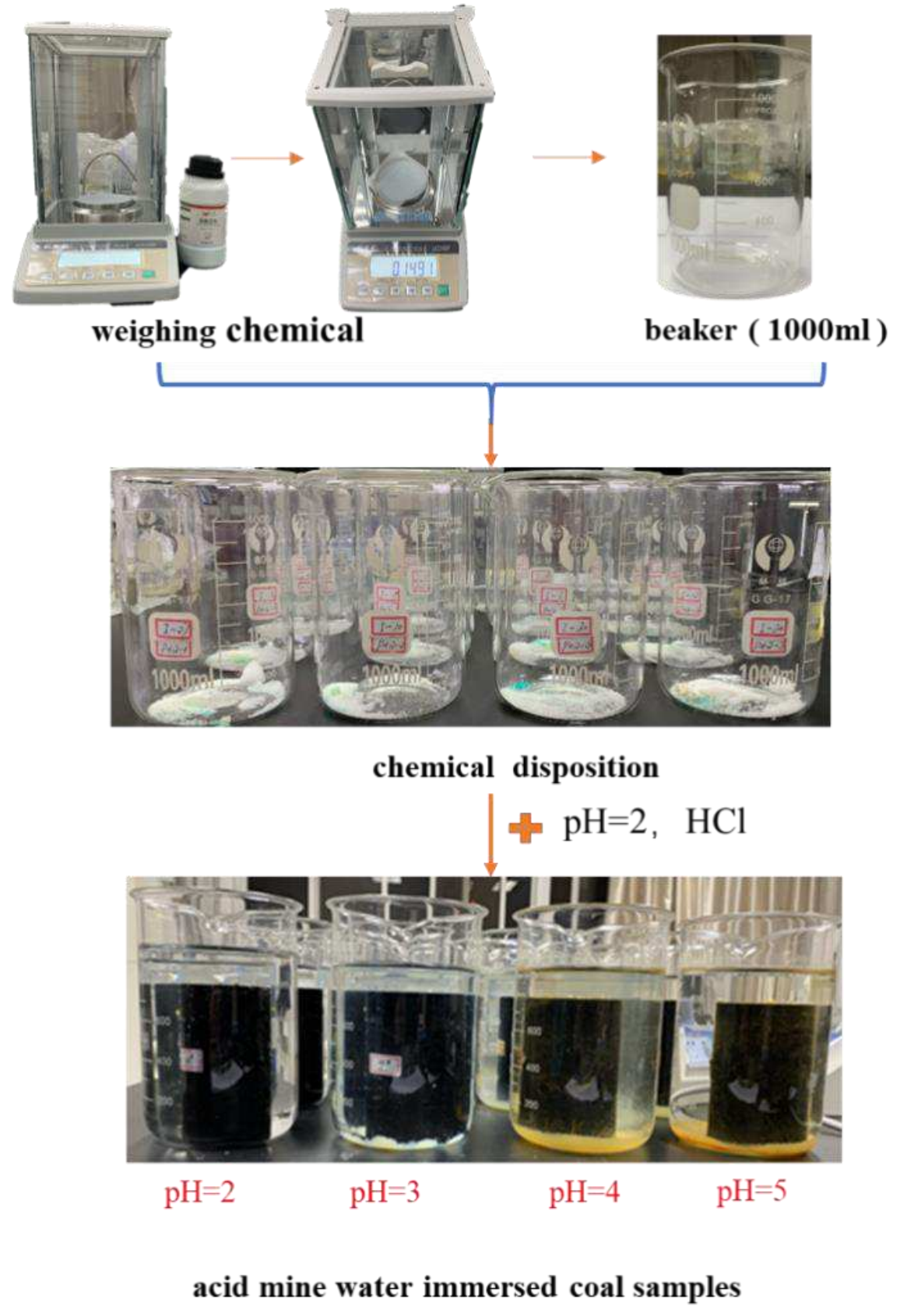

114 Static acid mine drainage immersion tests were performed on coal samples using 115 solutions with $\mathrm{pH}$ values of 2, 3, 4, and 5, for an immersion duration of $300 \mathrm{~h}$, according
Figure 3.Illustrations of the acid mine drainage preparation and coal samples immersion.

\subsection{Test process}

\subsubsection{Immersed coal test}


to previous studies ${ }^{26,27}$ (Fig. 4). During the initial 24 h, sampling was performed hourly, and every $12 \mathrm{~h}$ subsequently. Water quality parameters (pH, ORP, EC, and TDS) were measured after each sampling using a high precision C-600 multi-functional pen-type meter, until the end of each test. The precision and accuracy of the instrument for $\mathrm{pH}$, for example, were 0.01 and \pm 0.05 , respectively.

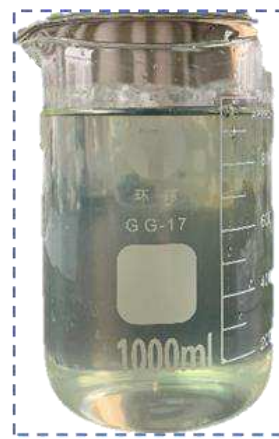

Acid mine water

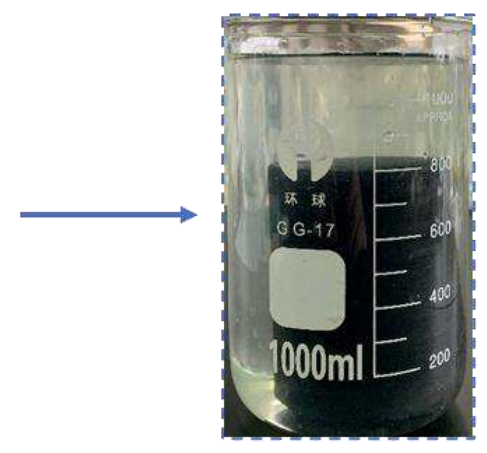

Immersed coal sample

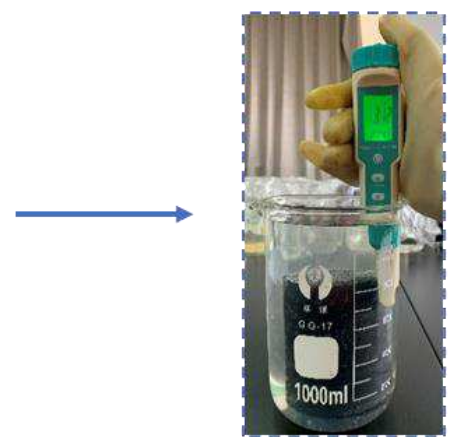

Immersed 10 hours

Figure 4. Diagram showing the main components of the acid mine drainage coal immersion test.

\subsubsection{SEM analysis}

SEM analyses were conducted on the coal samples after the immersion tests in the Laboratory for Green Coal Development in Shaanxi Province using a JSM-7610F (Japan) scanning electron microscope (Fig. 5). The instrument was equipped with a semi-immersion objective lens, a high-power optics illumination system, and two resolution modes $(15.0 \mathrm{kV}$ with $0.8 \mathrm{~nm}$ resolution and $1 \mathrm{kV}$ with $1 \mathrm{~nm}$ resolution). The high-resolution mode was selected for the analysis because of its superiority for examining the pore structure of coal samples. Samples were observed to evaluate microstructural changes in the coal samples at 2000x, 5000x, and 20,000x magnification. The coal slices used for SEM analyses were obtained by drying samples from the immersion tests at $60{ }^{\circ} \mathrm{C}$ (to prevent spontaneous combustion at high 

is illustrated in Fig.6.

138

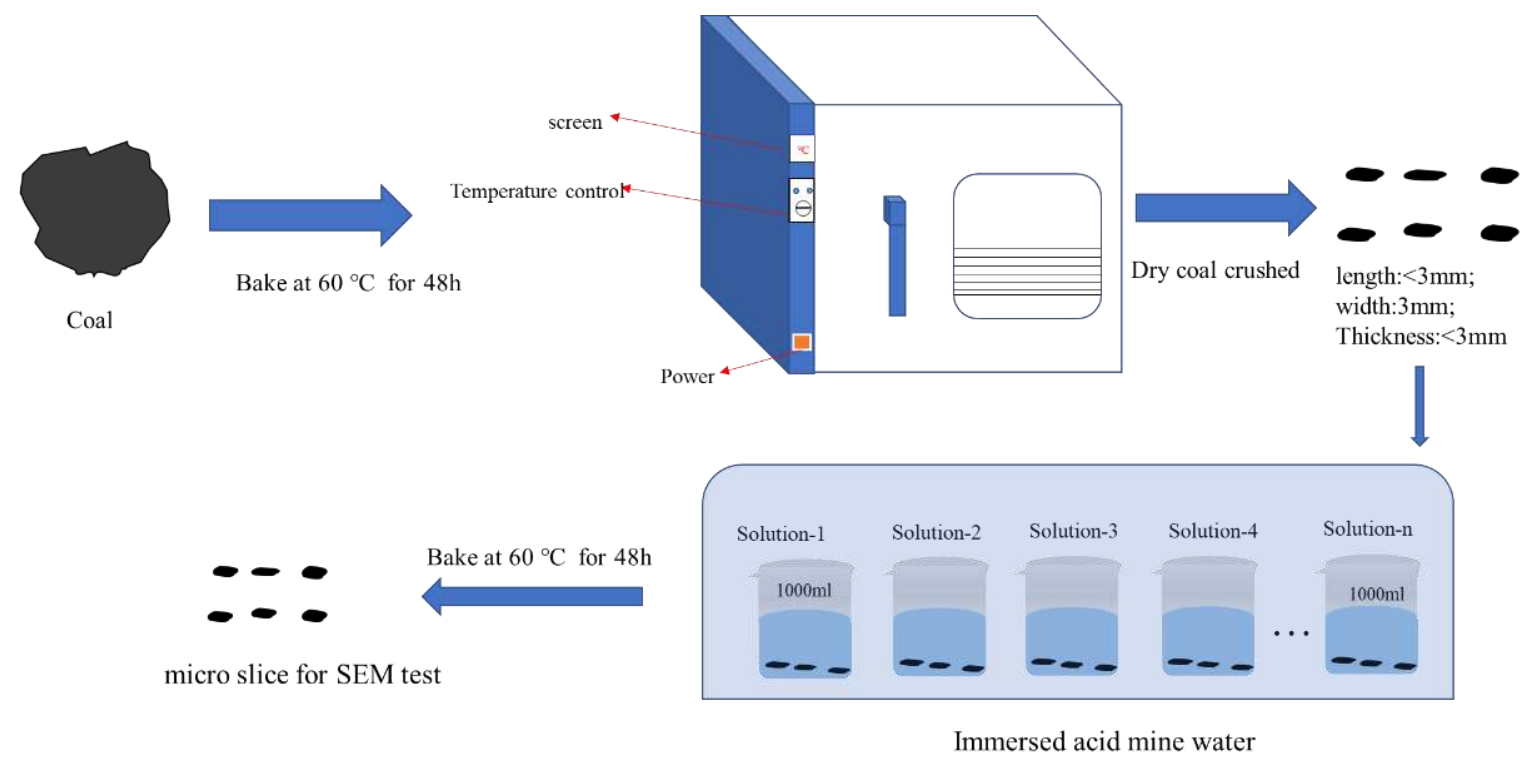

Figure 5.Scanning electron microscopy

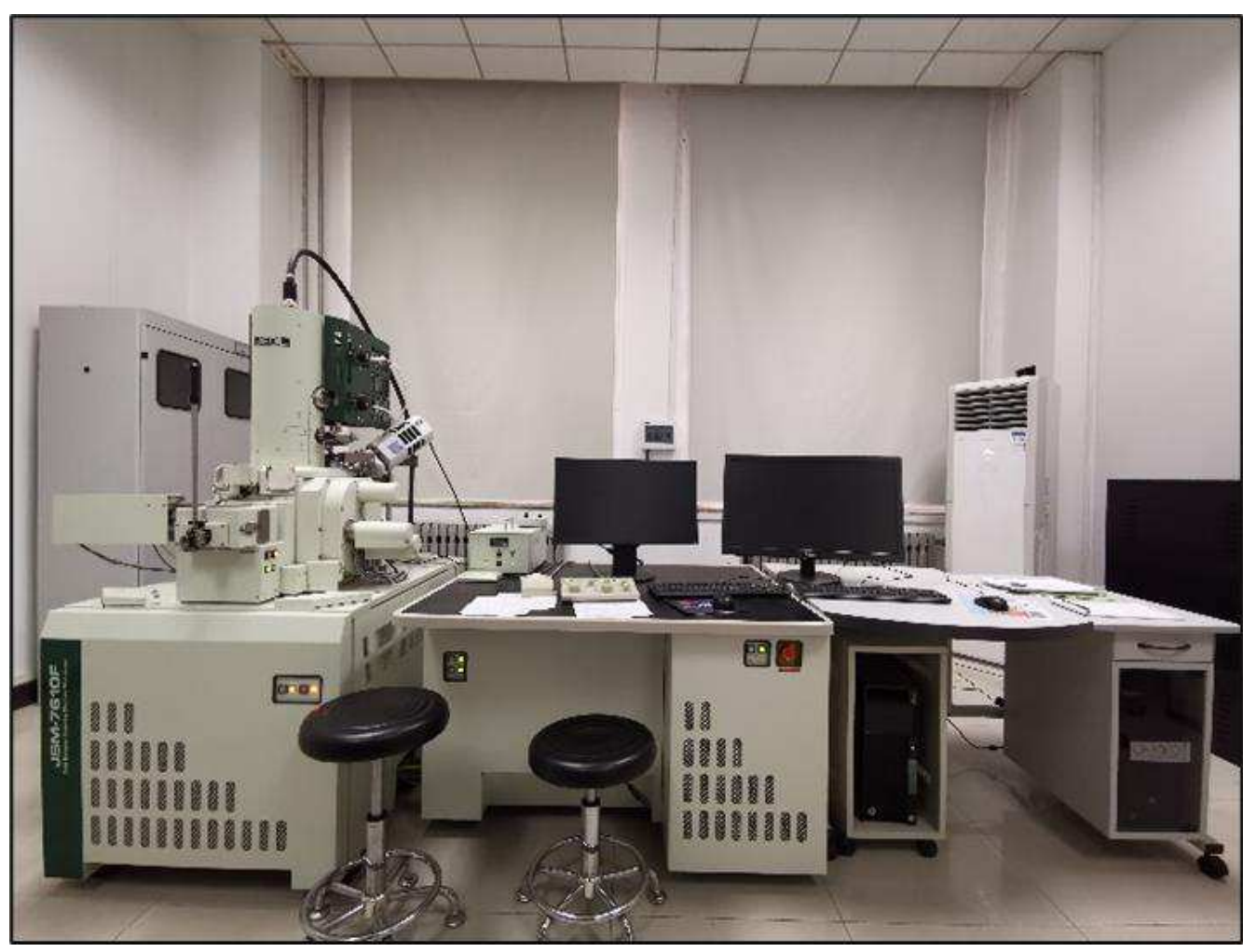




\subsection{The change of the $\mathrm{pH}$ value of the solution}

144 Experiments were conducted to assess changes in water quality parameters ( $\mathrm{pH}, \mathrm{ORP}$,

145 EC, and TDS) for the immersion solutions. The $\mathrm{pH}$ values of the solutions increased

146 with time, as displayed in Figure $7 \mathrm{a}$. The $\mathrm{pH}$ values of the $\mathrm{pH}-4$ and $\mathrm{pH}-5$ solutions

147 changed significantly from 4 and 5 to 6.8 and 7.3, respectively, whereas that of the $\mathrm{pH}$ -

$148 \quad 2$ solution barely increased from 2 to 2.08 .

149 The $\mathrm{pH}$ values of the immersion solutions increased by $4 \%, 30.67 \%, 70 \%$, and $46 \%$

150 relative to initial values of $2,3,4$, and 5 , respectively. $\mathrm{pH}$ changes variation after the

151 initial $12 \mathrm{~h}$ of coal samples immersion are shown in Figure $7 \mathrm{~b}$. During this phase, the

$152 \mathrm{pH}-2$ and $\mathrm{pH}-3$ solutions exhibit minor changes, the value for the $\mathrm{pH}-4$ solution

153 increased by $13.75 \%$ after $8 \mathrm{~h}$, and that for the $\mathrm{pH}-5$ solution showed a slight increase

154 after $10 \mathrm{~h}$ but increased by $3 \%$ during in the 11 th hour. 

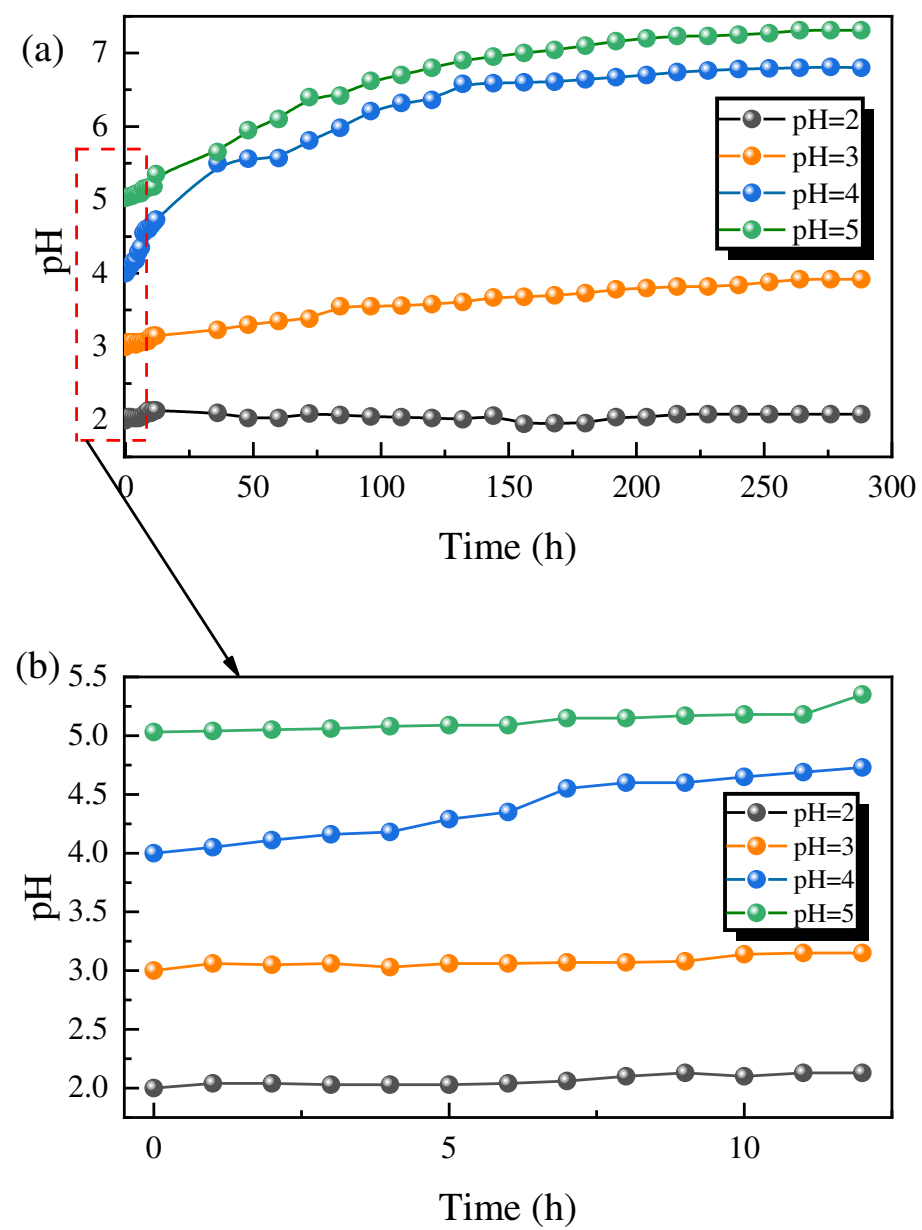

Figure 7. pH changes in immersion test solutions with initial pH values of 2, 3, 4, and 5 for (a) $300 \mathrm{~h}$ immersion duration and (b) $12 \mathrm{~h}$ immersion..

$\mathrm{pH}$ values of the solutions are correlated to the hydrogen contents of the coal samples.

159 After coal immersion, the $\mathrm{pH}$ values of solutions increased probably because of reactions involving feldspars (albite and K-feldspar) calcite, dolomite, and kaolinite.

162 the associated solutions ${ }^{28,29}$. These reactions include the following:

$\mathrm{NaAlSi}_{3} \mathrm{O}_{8}+4 \mathrm{H}_{2} \mathrm{O}+4 \mathrm{H}^{+} \rightarrow \mathrm{Na}^{+}+\mathrm{Al}^{3+}+3 \mathrm{H}_{4} \mathrm{SiO}_{4}$

$\mathrm{KAlSi}_{3} \mathrm{O}_{8}+4 \mathrm{H}_{2} \mathrm{O}+4 \mathrm{H}^{+} \rightarrow \mathrm{K}^{+}+\mathrm{Al}^{3+}+3 \mathrm{H}_{4} \mathrm{SiO}_{4}$

$\mathrm{CaCO}_{3}+2 \mathrm{H}^{+} \rightarrow \mathrm{Ca}^{2+}+\mathrm{CO}_{2}+\mathrm{H}_{2} \mathrm{O}$ 
$\mathrm{Al}_{2} \mathrm{Si}_{2} \mathrm{O}_{5}(\mathrm{OH})_{4}+6 \mathrm{H}^{+} \rightarrow 2 \mathrm{Al}^{3+}+2 \mathrm{H}_{4} \mathrm{SiO}_{4}+\mathrm{H}_{2} \mathrm{O}$

In Figure $7 \mathrm{a}$, the $\mathrm{pH}$ values initially increase and then stabilize, which indicates that reactions between soluble minerals in coal and acidic solutions attain equilibria involving significant buffering phase ${ }^{30-32}$. In addition, changes in the $\mathrm{pH}-4$ and $\mathrm{pH}-5$ solutions are pronounced relative to those for the $\mathrm{pH}-2$ and $\mathrm{pH}-3$ solutions. These differences are because the lower $\mathrm{pH}$ solutions contained 10-100 times more hydrogen ions compared with the higher $\mathrm{pH}$ solutions, whereas the coal samples involved comparable minerals contents. Therefore, the higher $\mathrm{pH}$ solutions displayed more pronounced acidity changes when an equal amount of hydrogen ions was consumed.

\subsection{Oxidation-reduction potential (ORP) changes}

Changes in ORP values for the simulated acid mine drainage solutions after coal immersion are displayed in Figure 8(a). Overall, the ORP values decrease as the immersion times increase, with values changing 444 to 436,161 to 119,108 to -63 , and 65 to $-118 \mathrm{mV}$ for the $\mathrm{pH}-2, \mathrm{pH}-3, \mathrm{pH}-4$, and $\mathrm{pH}-5$ solutions, respectively. Relative to the original solutions, ORP values decreased by $2.7 \%(\mathrm{pH}-2), 26.1 \%(\mathrm{pH}-3), 158.3 \%$ (pH-4), and 281.5\% (pH-5), after the immersion tests. These values highlight changes in the oxidation potential of the immersion solutions. Ultimately, the ORP values for solutions with initial $\mathrm{pH}$ values of 4 and 5 change from positive to negative, and the negative ORP values are significantly higher, indicating an overall negative trend. 


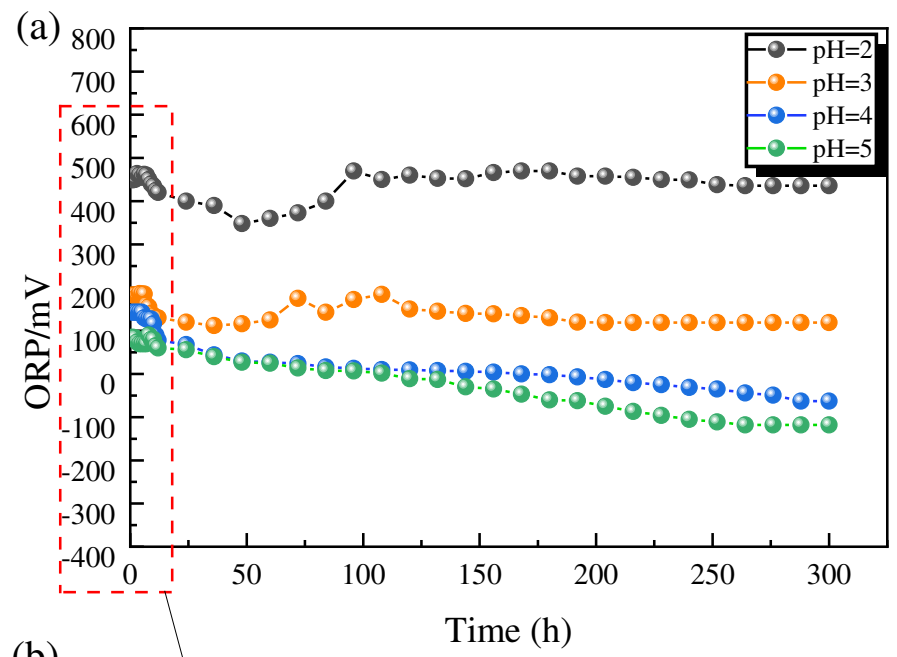

(b)

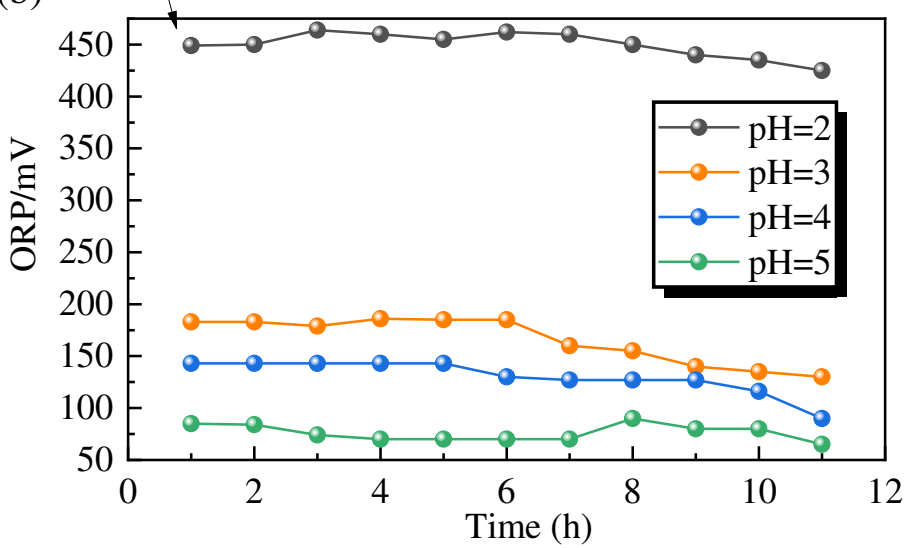

Figure 8. Plot showing changes in ORP values for acidic solutions after coal immersion for (a) $300 \mathrm{~h}$ and (b) $12 \mathrm{~h}$.

The $\mathrm{pH}-2$ solution is characterized by high ORP values in the period between $2-4 \mathrm{~h}$ after the immersion test begins, and then this decreases continuously until it stabilizes around $200 \mathrm{~h}$. Regarding the $\mathrm{pH}-4$ and $\mathrm{pH}-5$ solutions, the ORP values increased during the first hour, and then decreased progressively during the rest of the test duration. The potentials exhibit negative trends, with values stabilizing at around $-63 \mathrm{mV}(\mathrm{pH}-4)$ and $-118 \mathrm{mV}(\mathrm{pH}-5)$ after $250 \mathrm{~h}$. In Figure $8 \mathrm{~b}$, changes in ORP values for the four acidic solutions after coal immersion for $12 \mathrm{~h}$ are displayed. The ORP values slightly increase between 1 and $8 \mathrm{~h}$, and then decrease until stable values are attained.

In Figure $8 \mathrm{~b}, \mathrm{ORP}$ values for the $\mathrm{pH}-2$ and $\mathrm{pH}-3$ solutions decrease and increase from 
10 to $100 \mathrm{~h}$ because of the oxidation of pyrite in the coal samples. This reaction produces $\mathrm{H}^{+}$in a strong acid environment ${ }^{30-32}$, which enhances the oxidation potential of the solution and the ORP. This reaction can be expressed as follows:

$$
2 \mathrm{FeS}_{2(\mathrm{~s})}+2 \mathrm{H}_{2} \mathrm{O}+7 \mathrm{O}_{2} \rightarrow 4 \mathrm{H}^{+}+\mathrm{SO}_{4}^{2-}+2 \mathrm{Fe}^{2+}
$$

The ORP value highlights the redox strength of a solution, with acidic solutions characterized by high ORP values. A gradual change of the ORP value from positive to negative indicates that the oxidation potential of the solution decreased by However, the hydrogen ion content represents the acidity of the solution, and this directly affects its oxidation potential. Therefore, the immersion of coal samples gradually increased the $\mathrm{pH}$ values of the four acidic solutions, which indicates weakening of their oxidation potentials after $300 \mathrm{~h}$, with the ORP values decreasing by $2.7 \%(\mathrm{pH}-2), 26.1 \%(\mathrm{pH}-3)$, $158.3 \%(\mathrm{pH}-4)$, and $281.5 \%(\mathrm{pH}-5)$.

\subsection{EC changes in the immersion solutions}

The electrical conductivity (EC) changes exhibit trends similar to those for $\mathrm{pH}$ values of the solutions. In fact, the $\mathrm{pH}$ and EC values attain stability around the same time (200 h), and dynamic equilibria were achieved in the reactions between the aqueous solutions and the immersed coal samples ${ }^{20}$, before gradually increasing with time. Changes in the EC values of the solutions, however, differ, with values varying between 21,000-22,500, $8,100-8,880,7,300-8,150$, and 5,250-6,250 $\mu \mathrm{S} / \mathrm{cm}$ for the $\mathrm{pH}-2, \mathrm{pH}-3, \mathrm{pH}-4$, and $\mathrm{pH}-$ 5 solutions, respectively.

The EC values amplification were 1,500, 780, 880, and 1,000 for $\mathrm{pH}-2, \mathrm{pH}-3, \mathrm{pH}-4$, 
and $\mathrm{pH}-5$ solutions, respectively. Considering changes in the EC values and the increase relative to the original EC values, the magnitudes of changes in EC values among the solutions are similar, although the $\mathrm{pH}-2$ solution produced the maximum increase. The EC values increase in the solutions follow the order $\mathrm{pH}-2>\mathrm{pH}-5,>\mathrm{pH}-4>\mathrm{pH}-3$

(Figure 9).

224

(a)

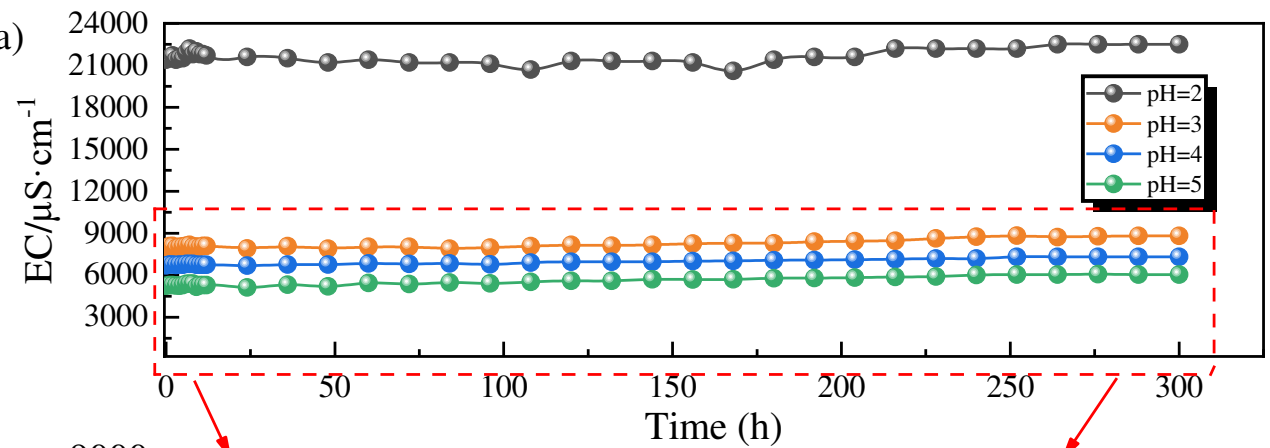

(b)

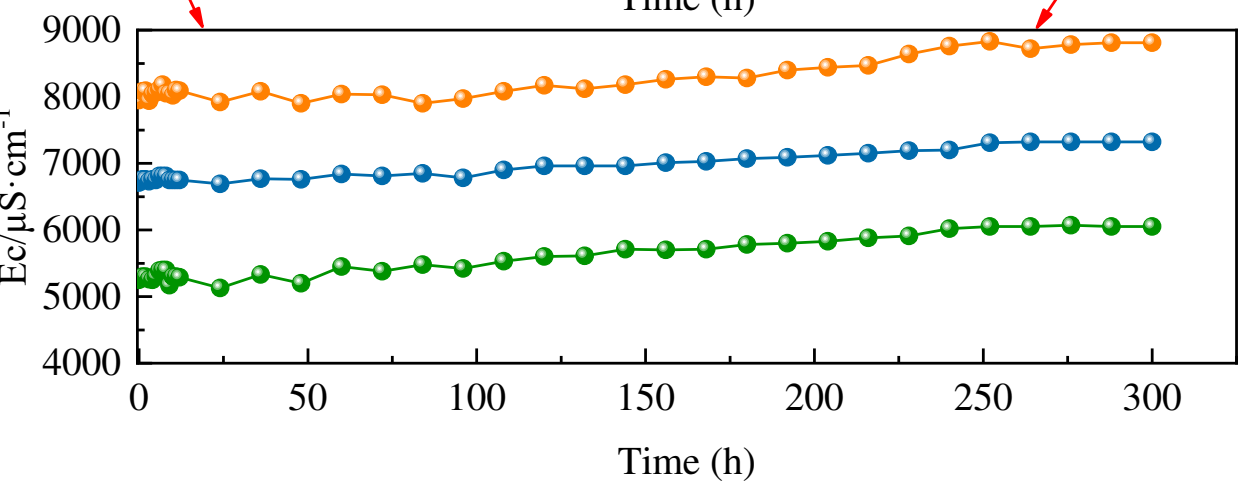

Figure 9. Changes in electrical conductivity values of acidic solutions (pH values of 2 5) for (a) the test duration of $300 \mathrm{~h}$ and (b) relative to the original EC value.

\subsection{TDS changes in the solutions}

The EC and TDS are closely related because an increase in the EC value indicates an increase in the conductive ions content of a solution ${ }^{20}$. The TDS of the immersion solutions changed significantly (Figure 10), and these were accompanied by changes in

$231 \mathrm{pH}$ values from 5 to 4, and then to 3. Changes in EC values of the solutions are similar, although the pH-2 solution showed TDS contents between 15-16 ng/L. The TDS for 
pH-2 is, however, approximately 6 orders of magnitude higher than those for the

234 solutions with initial $\mathrm{pH}$ values of 3,4 , and 5 . This is because the acidity of the $\mathrm{pH}-2$

235 solution is higher than those of the other solutions, and thus, precipitation and re-

236 dissolution occurred in this strongly acidic environment. Therefore, although the solid

237 content of the solution was lower, the dissolved ions content increased. Therefore, the

$238 \mathrm{pH}-2$ solution yielded EC values varying between $21,000-22,500 \mu \mathrm{S} / \mathrm{cm}$, which are

239 clearly higher than those of the other solutions.

240 TDS values of the $\mathrm{pH}-2, \mathrm{pH}-3, \mathrm{pH}-4$, and $\mathrm{pH}-5$ solutions (Figure 10a) correspondingly

241 increased by $8.0 \%, 11.1 \%, 8.8 \%$, and $17.8 \%$. In Figure $10 \mathrm{~b}$, TDS values increase during

242 the $1^{\text {st }}$ hour, decrease in the $4^{\text {th }}$ hour, and then increase again in the $5^{\text {th }}$ hour. TDS values

243 during the $12^{\text {th }}$ hour indicate that the initial coal degradation process by the acidic

244 solution is dynamic. As the immersion time increases, the reactions stabilize and the

245 TDS value gradually increase. 


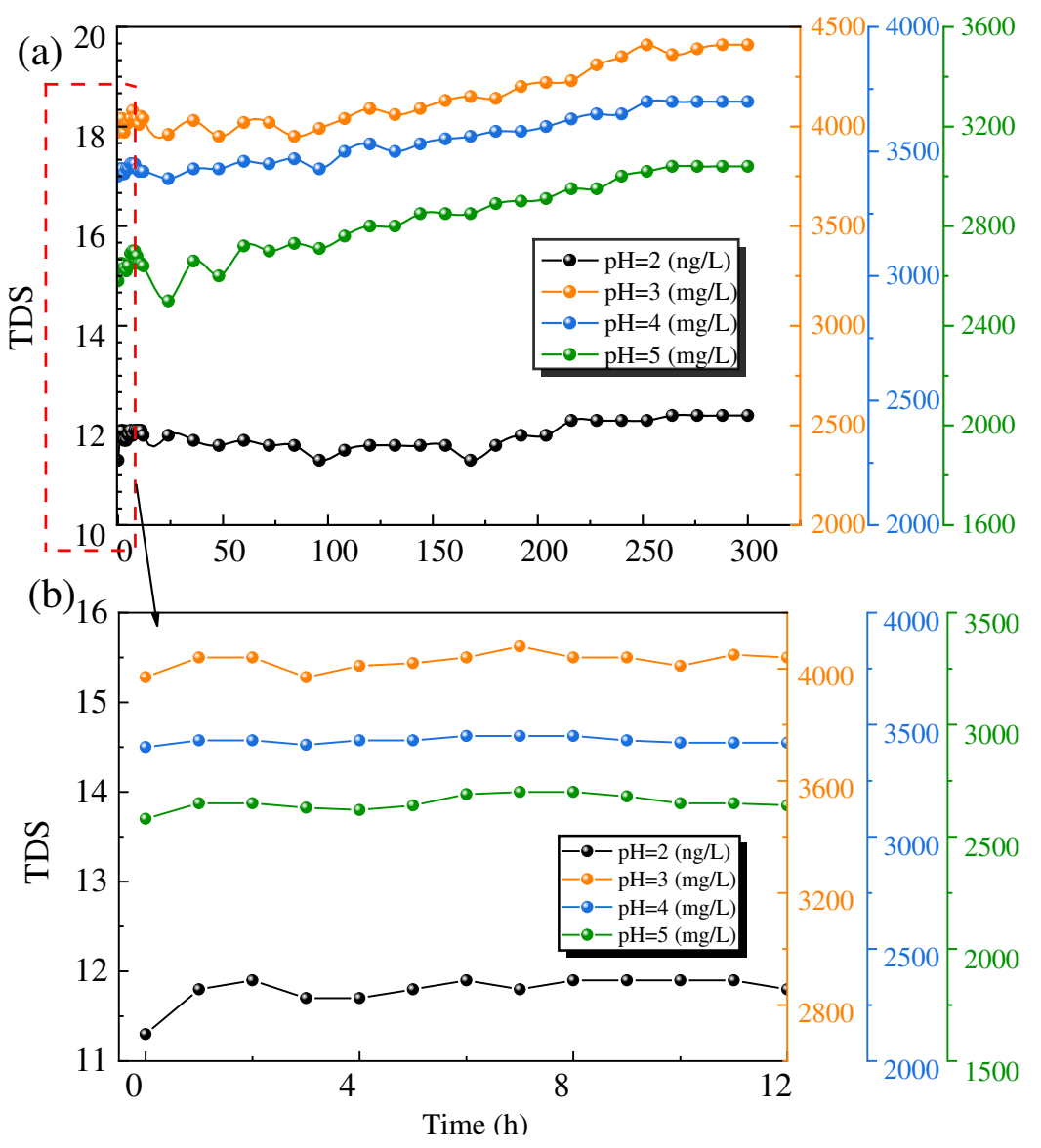

Figure 10. TDS changes in acidic solutions with initial $\mathrm{pH}$ values of $2,3,4$, and 5 for (a) $300 \mathrm{~h}$ and (b) the initial $12 \mathrm{~h}$..

\subsection{Micropore characteristics of acid-etched coal samples}

\subsubsection{Morphological characteristics of coal exposed to different immersion solutions}

252 Microstructures of coal samples immersed in different acidic solutions are displayed in

Fig. 11. Evidently, the morphology of pores in the coal samples are significantly altered by immersion in the acid solutions. The coal samples surfaces are characterized by roughnesswas disrupted by caused by the acidic solutions, with increasing randomness as the acidity increases (Fig. 11a-d). The acidity of the solutions influenced the pore throat size and geometry in the coals, with the pore throat size significantly increasing from the highest to the lowest $\mathrm{pH}$ solution (marked by the red box in Fig. 11). The pores 
mainly exhibit surface carbon base erosion, and this indicates pore development, as

260 shown in the frame of dashed lines in red. As the acidity of the solution increases, larger

261 pores are more evident and higher in number, as shown by the box with lines in red in

262 Fig. 11b-d.
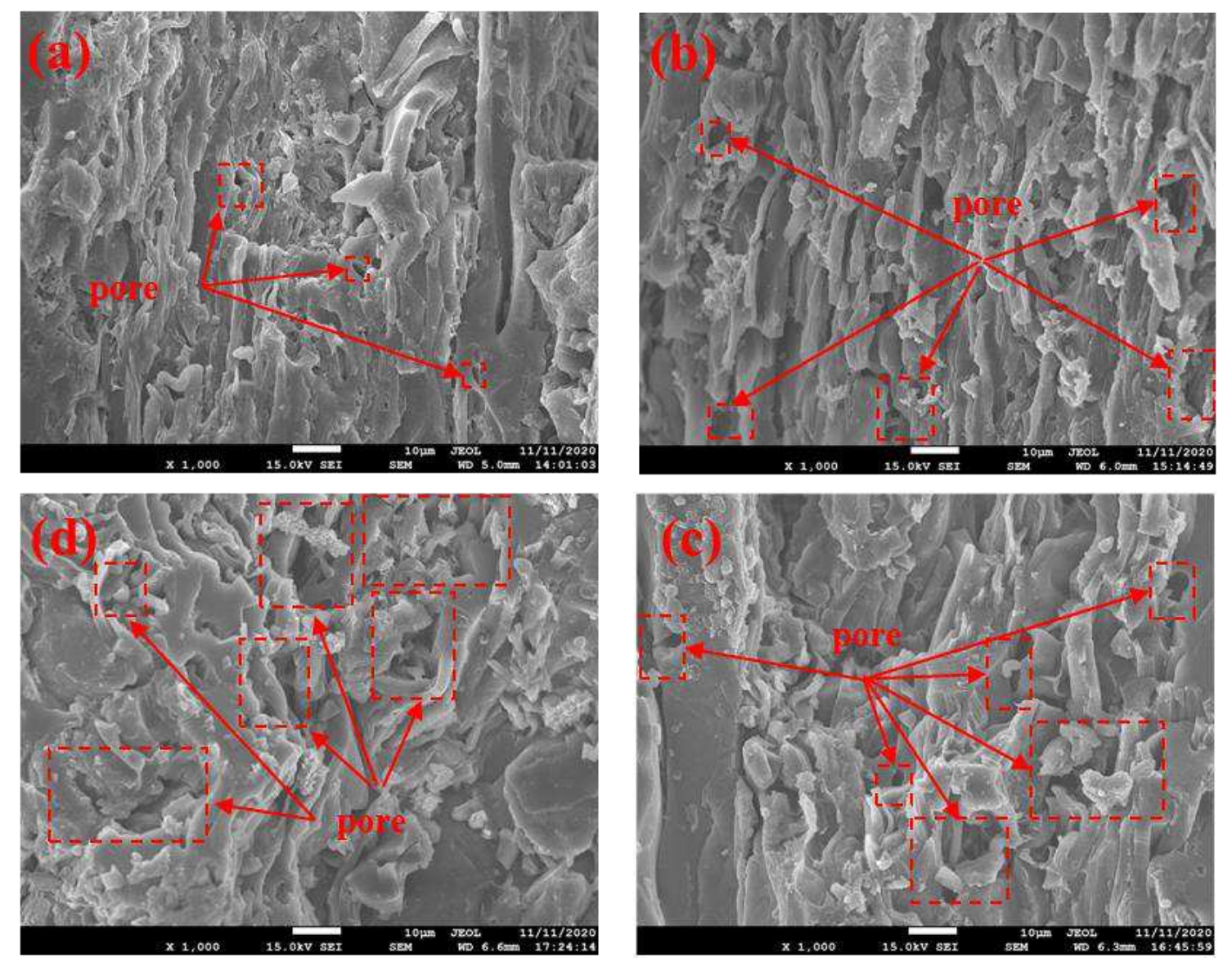

Figure 11. Morphology of coal samples immersed in acidic solutions including (a) pH-5, (b) $\mathrm{pH}-4$, (c) $\mathrm{pH}-3$, and (d) $\mathrm{pH}-2$.

Coal pores in Fig. 12 reveal variable alterations in pore sizes and pore walls roughness

267 by the acidic solutions. As the $\mathrm{pH}$ decreases, the throat pore sizes obviously increase,

268 while the pore walls change from smooth and flat to rough. In Fig. 12a, the image

269 obtained at 20,000x magnification reveals smooth and intact pore walls with minor

270 accumulated amount particulate matter. However, as the acidity increased, the

271 roughness of pore walls increased, and cracks (Fig. 12b-c) or scale-like step marks (Fig. 

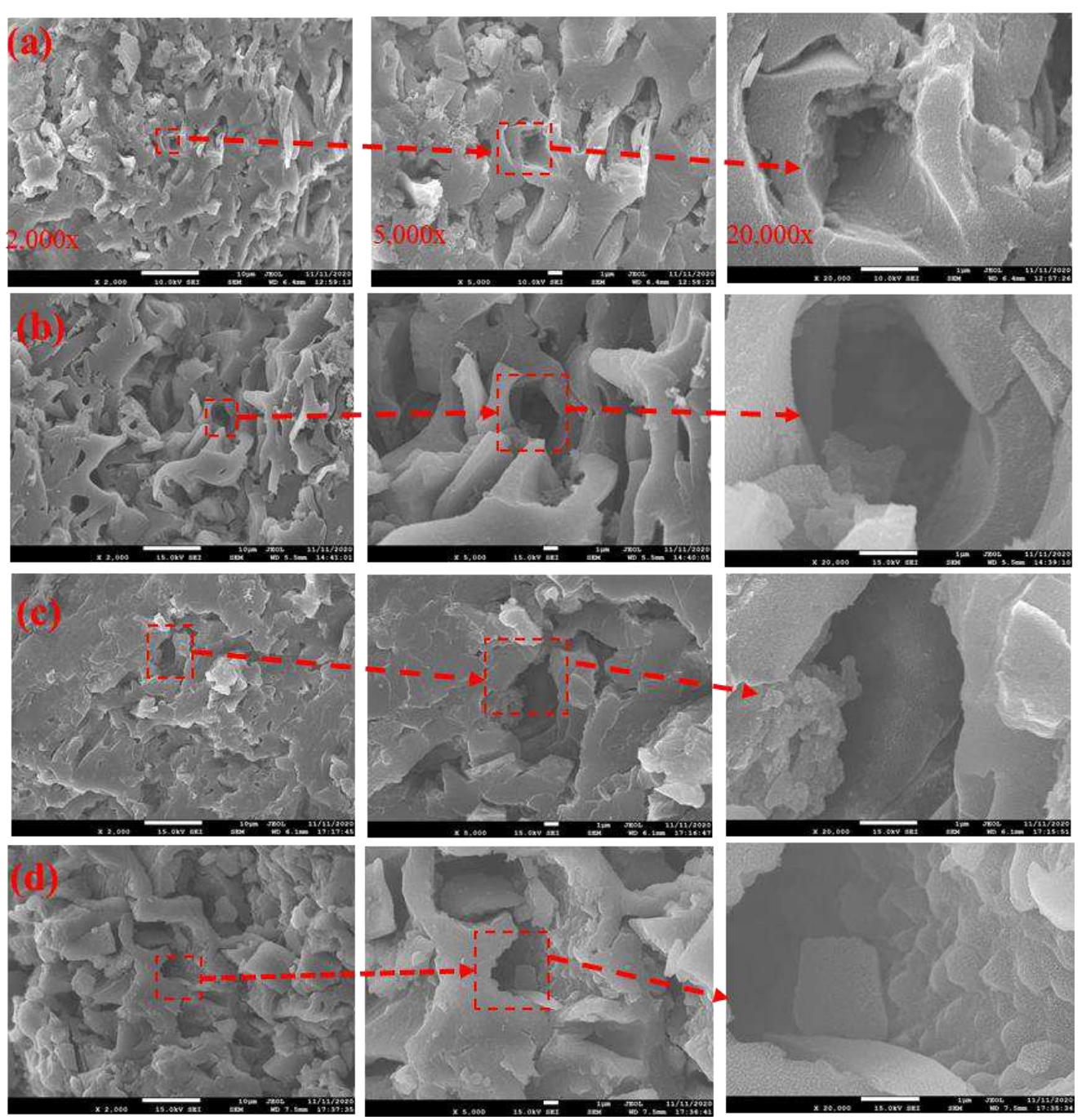

Figure 12. Morphology of pores in coal exposed to acidic solutions including (a) pH-5,

(b) $\mathrm{pH}-4$, (c) $\mathrm{pH}-3$, and (d) $\mathrm{pH}-2$, The magnification from left to right are: $2,000 \mathrm{x}$, $5,000 x$, and 20,000x .

\subsubsection{Quantitative analysis of pore space in the immersed coals}

281 To quantitatively characterize the influence of various solutions on coal pores, we 
cracks (i.e., white for pores and black for particles in the binarized image) $)^{34}$. The fissures associated with various acidic conditions, as illustrated in Fig. 13.
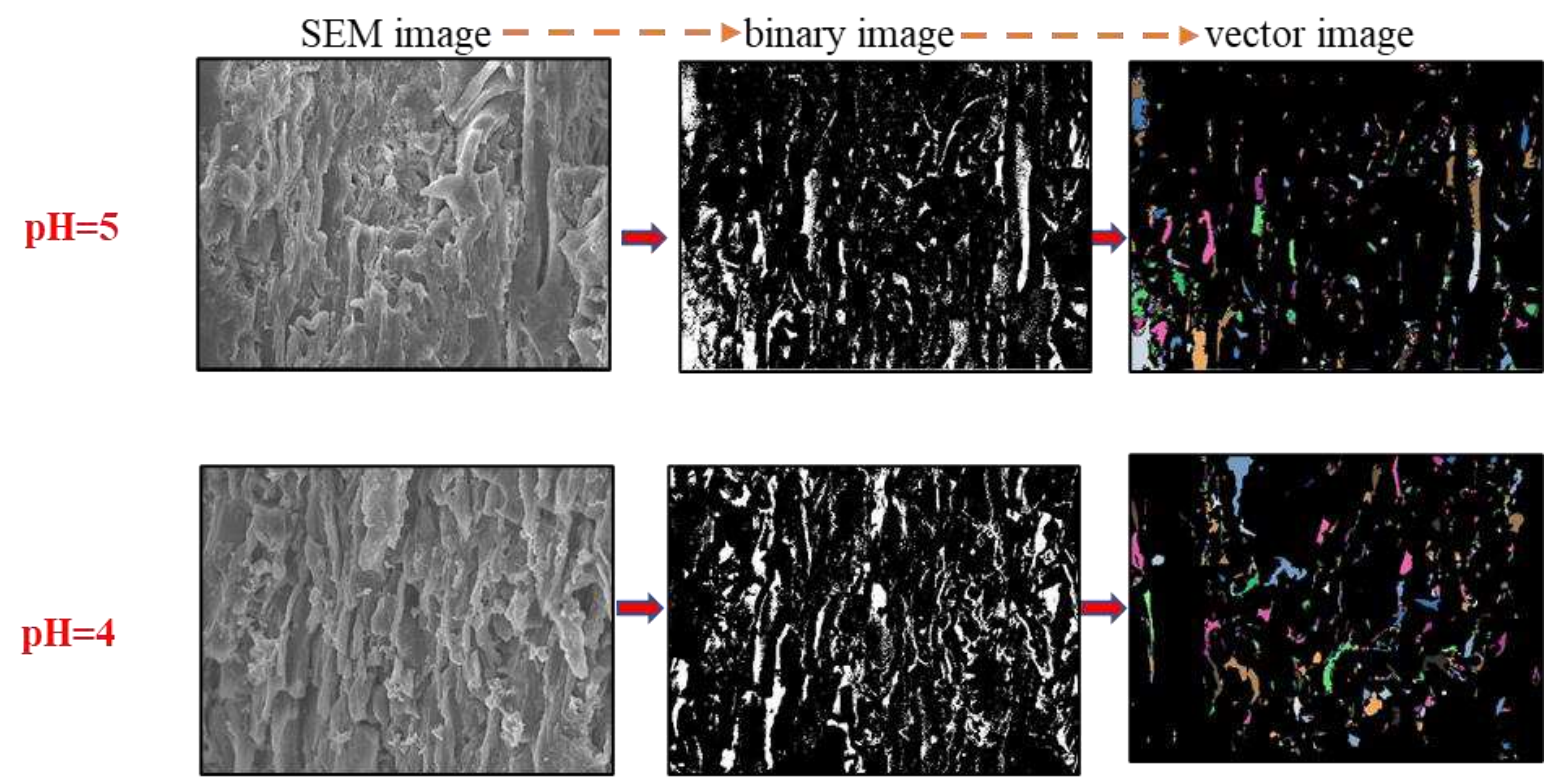

Figure 13. Illustration of the identification and analysis process of coal pores using the PCAS software at 1,000x magnification .

290 Through the PCAS, binarized and vectorized images were analyzed after image

291 processing to extract the area and orientation of pores in the coals. The extracted pore

292 area pixels were then utilized to calculate equivalent pore throat sizes in the coal

293 samples ${ }^{34}$, and the results are presented in Table 3. 
Table 3 Statistics on the number and distribution of pores in coals immersed in solutions of

\begin{tabular}{lcccccccc}
\hline \multirow{2}{*}{$\begin{array}{l}\text { Pore diameter } \\
(\mu \mathrm{m})\end{array}$} & \multicolumn{2}{c}{$\mathrm{pH}=5$} & \multicolumn{2}{c}{$\mathrm{pH}=4$} & \multicolumn{2}{c}{$\mathrm{pH}=3$} & \multicolumn{2}{c}{$\mathrm{pH}=2$} \\
\cline { 2 - 9 } & Quantity & Proportion & Quantity & Proportion & Quantity & Proportion & Quantity & Proportion \\
\hline $4-10$ & 427 & 0.879 & 443 & 0.820 & 360 & 0.829 & 416 & 0.761 \\
\cline { 2 - 9 } $10-16$ & 34 & 0.070 & 61 & 0.113 & 45 & 0.104 & 62 & 0.113 \\
$16-24$ & 15 & 0.031 & 23 & 0.043 & 20 & 0.046 & 39 & 0.071 \\
\hline 24 & 10 & 0.021 & 13 & 0.024 & 9 & 0.021 & 30 & 0.055 \\
\hline
\end{tabular}

296 According to the PCAS analysis and calculations, pore sizes produced the following

297 ranges: $4-10,10-16,16-24$, and $>24 \mu \mathrm{m}$. Variations in the equivalent pore size and

298 orientation of coal samples immersed in solutions of varying $\mathrm{pH}$ are displayed in Fig.

299 16. In the sample immersed in the $\mathrm{pH}-5$ solution, the proportion of pores varying

300 between $4-10 \mu \mathrm{m}$ is 0.879 , but this proportion gradually decreases with increasing

301 acidity to approximately 0.761 in the sample immersed in the $\mathrm{pH}-2$ solution, while

302 proportions of pores with throat sizes between 10-16, 16-24, and $>24 \mu \mathrm{m}$ increased

303 significantly. The proportion of pores $>24 \mu \mathrm{m}$ in size increased from 0.021 (for the $\mathrm{pH}-$

3045 solution) to 0.055 (for the $\mathrm{pH}-2$ solution), as shown in Fig. 14. Changes in the

305 proportions of pore sizes indicate that the more acidic solution continuously eroded coal

306 pores, thereby increasing pore sizes and promoting microstructural development in the

307 direction of large pores. This increase in the number of large pores enhanced the

308 porosity of the coal. Calculated porosities are $9.8 \%, 11.73 \%, 18.91 \%$, and $20.75 \%$, for

309 the $\mathrm{pH}-5, \mathrm{pH}-4, \mathrm{pH}-4$, and $\mathrm{pH}-2$ solutions, respectively. 
(a)

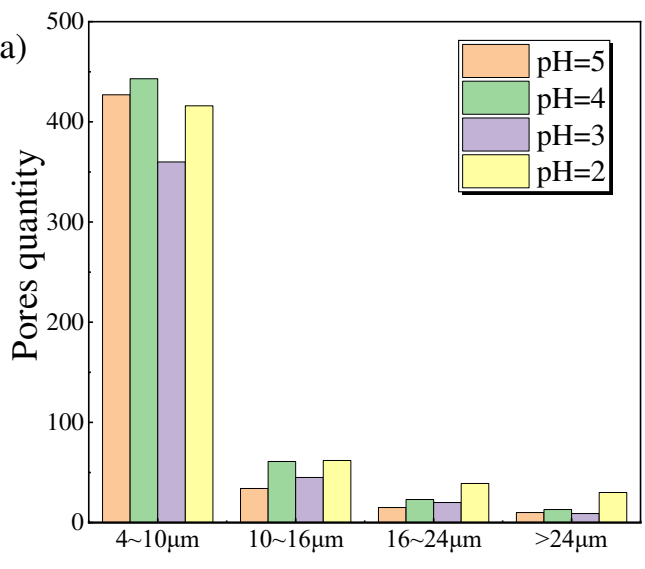

Pores diameter

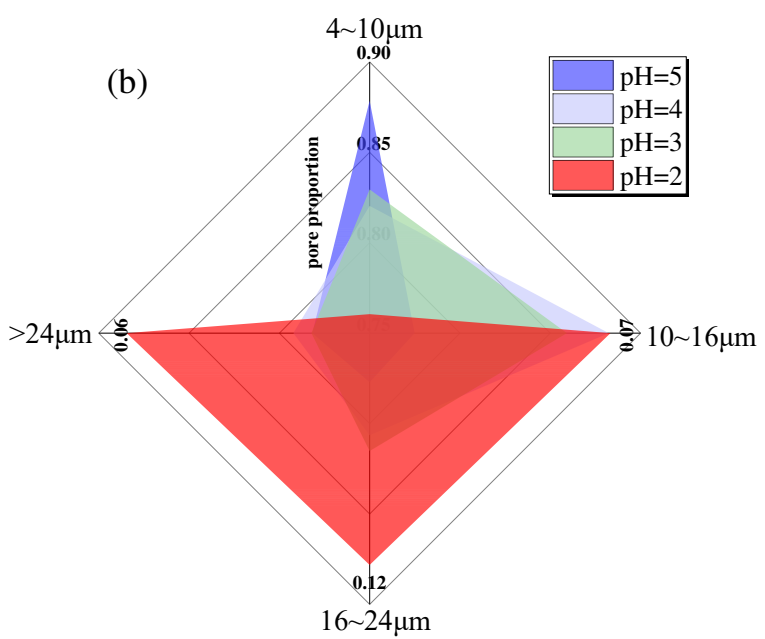

Figure 14. Quantitative analysis coal pore characteristics including the (a) distribution of pore throat diameters and (b) proportions of various pore diameters.

The pore orientation distributions of coal samples immersed in different acidic solutions

are displayed in Fig. 15, with the orientation determined as the dominant direction of

pores. Based on the PCAS analysis, the following pore orientation ranges were obtained:

$0-30^{\circ}, 30-60^{\circ}, 60-90^{\circ}, 90-120^{\circ}, 120-150^{\circ}$, and $150-180^{\circ}$.

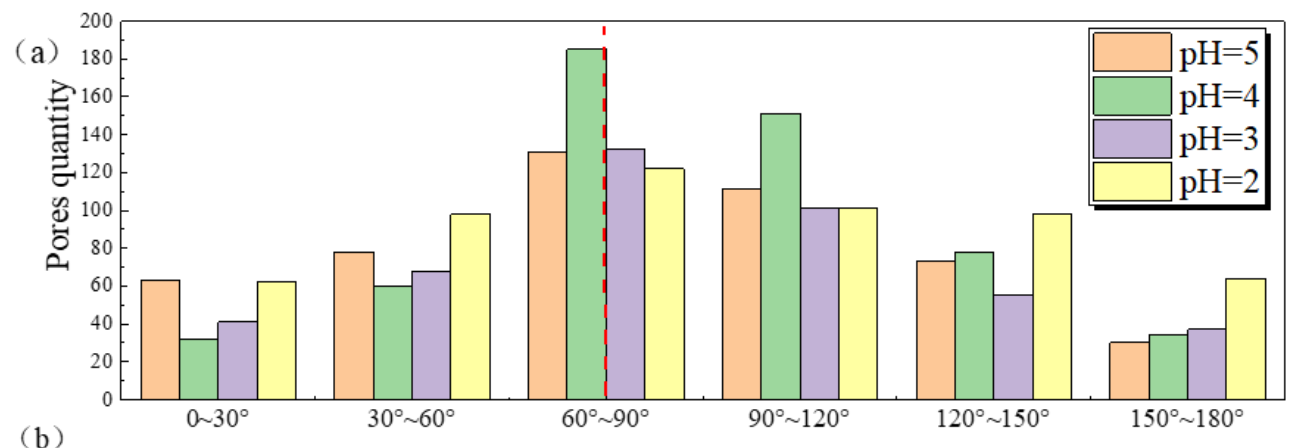

(b)

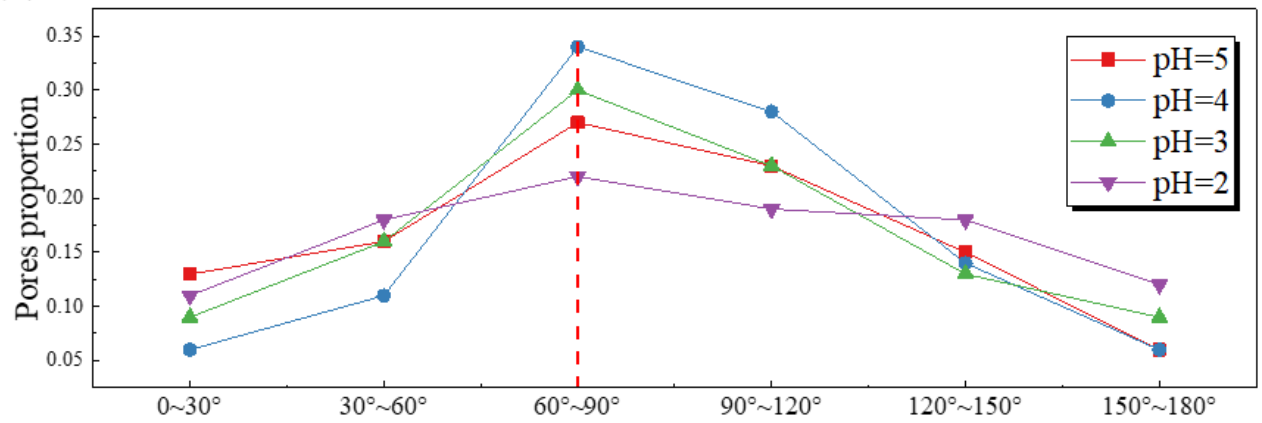

Direaction

Figure 15. Orientation of coal pores associated with different acidic solutions including the (a) pore orientation distribution and (b) proportion of pores in different orientation ranges.

Pores with orientations between $60-90^{\circ}$ are dominant (Fig. 15a), with approximately 
pores gradually decrease. Therefore, pores mostly adopted the $60-90^{\circ}$ range orientation, with the asymmetric axis (the dashed line in red in Fig. 15a and b) dividing the left and right parts. However, acidity affected the proportion of pore orientations, thereby altering the extent of leveling of the left and right sections of the asymmetric axis. In changing from a weak (pH-5) to a strong ( $\mathrm{pH}-2)$ acid environment, the $60-90^{\circ}$ oriented pore proportion increased from $0.27(\mathrm{pH}-5)$ to $0.34(\mathrm{pH}-4)$, and then to $0.30(\mathrm{pH}-3)$, and finally to $0.22(\mathrm{pH}-2)$.

However, the pore orientation proportion initially increased and then decreased. Owing to the decrease in pores with $60-90^{\circ}$ orientations, the distribution plot is flat (purple line in Fig. $15 \mathrm{~b}$ ), while the pore orientation dominance gradually shifts to the $120-150^{\circ}$ and $150-180^{\circ}$ ranges. The dominant pore orientation shift indicates that the strong acidic solution decreases pores with the dominant orientation through erosion, while increasing the number of pores with other orientations, thereby imparting a random morphology.

Figure 16(a)-(b) shows that the proportion of coal pores associated with various orientations form three groups, as the acidity of the solution decreased. These groups include the following: one involving an initial increase followed by a decrease, another characterized by decrease and subsequent increase, and the last showing continuous increase. The trend involving an increase followed by a decrease is most common for the $60-90^{\circ}$ and $90-120^{\circ}$ orientation ranges, in which porosities attained maximum values in the pH-4 solution. However, porosity gradually decreased as the acidity increased, with the lowest value associated with the $\mathrm{pH}-2$ solution. 

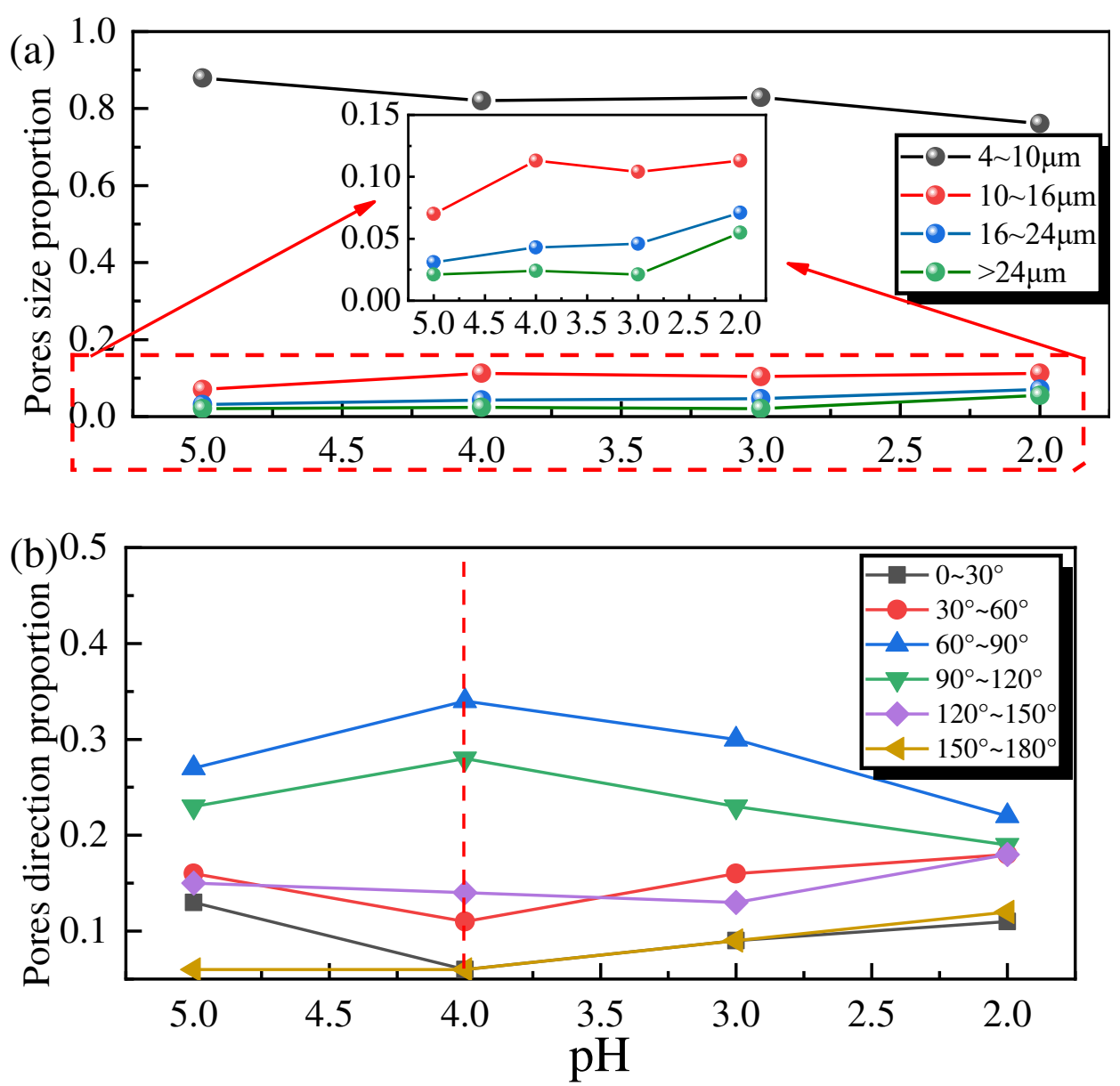

Figure 16. Effect of acidic solutions with different $\mathrm{pH}$ on structural parameters of coal pores including the relationship between (a) solution $\mathrm{pH}$ and pore size and (b) solution pH and pore direction .

This trend involving a decrease followed by an increase occurred for porosities in the $0-30^{\circ}, 30-60^{\circ}$, and $120-150^{\circ}$ orientation ranges. These occurred such that porosities in the $0-30^{\circ}$ and $30-60^{\circ}$ ranges attained minimum values in the $\mathrm{pH}-4$ solution, and the porosities gradually increased with increasing acidity, thereby producing the maximum porosities in the $0-30^{\circ}$ and $30-60^{\circ}$ ranges. This trend was contrary to that in the $60-$ $90^{\circ}, 90-120^{\circ}$, and $120-150^{\circ}$ ranges until a $\mathrm{pH}$ of 3 was attained, and the decline in porosity ceased. At a $\mathrm{pH} 2$, the porosity increased, and the pore orientation is dominated by the $150^{\circ}-180^{\circ}$ range.

Figure $16 \mathrm{~b}$ shows that porosity patterns dominating in acidic environments differ 
because a strongly acidic environment likely alters pore orientations. This variation is evident in Fig. 16b, with the dashed line in red at an initial $\mathrm{pH}$ of 4 , delineating the three types of pore orientation changes.

In summary, microstructures of the coal samples were significantly altered by various acidic solutions, as illustrated by the gradual increase in the proportion of large pores with increasing acidity, the shift in predominant pore orientation with increasing acidity from the $60-90^{\circ}$ range, and the increase in the proportion of pores with the $150-180^{\circ}$ and $0^{\circ}-30^{\circ}$ orientations.

\section{Conclusion}

1. The $\mathrm{pH}, \mathrm{ORP}, \mathrm{EC}$, and TDS of the immersion solutions changed after the immersion of coal samples. The $\mathrm{pH}, \mathrm{EC}$, and TDS increased after the immersion tests, while the ORP value changed from positive to negative. The $\mathrm{pH}-4$ and $\mathrm{pH}-5$ solutions showed the highest $\mathrm{pH}$ increases, with $70 \%$ and $46 \%$, respectively, while EC values of the solutions also increased correspondingly by $12 \%$ and $19 \%$. TDS changes were highest for the $\mathrm{pH}-3, \mathrm{pH}-4$, and $\mathrm{pH}-5$ solutions, with corresponding changes of $11.1 \%, 8.8 \%$, and $17.8 \%$.

2. Variations in pore throat sizes of the coals were associated with the acidity of the simulated acid mine drainage. As the $\mathrm{pH}$ of the acidic solution decreased, the proportion of large pore throat sizes $(10-16,16-24$, and $>24 \mu \mathrm{m})$ in the SEM images of the coals gradually increased, highlighting porosity development and severe pore morphology alteration. 
3. Acidic solutions with different $\mathrm{pH}$ values changed pore throat sizes and pore orientations in the coal samples. Pore orientation dominance gradually changed from the $60-90^{\circ}$ range to the $0-30^{\circ}$ and $150-180^{\circ}$ ranges with increasing acidity. These changes increased randomness in pore orientations, which was accompanied by severe damage on the surfaces of the coal samples.

\section{Acknowledgments}

This study is supported by the Natural Science Basic Research Program (2020-JQ745) of the Shaanxi Provincial Science and Technology Department and the Shaanxi Provincial Coal Green Development Geological Support Experiment. We would like to thank Editage (www.editage.cn) for English language editing.

\section{References}

1. Acharya, B. S. \& Kharel, G. Acid Mine Drainage From Coal Mining in the United States an Overview. Journal of hydrology (Amsterdam). 588, 125061 (2020).

2. Cherry, D. S., Currie, R. J., Soucek, D. J., Latimer, H. A. \& Trent, G. C. An Integrative Assessment of a Watershed Impacted by Abandoned Mined Land Discharges. Environ. Pollut. 111, 377-388 (2001).

3. Xu, D. et al. Leaching Behavior of Heavy Metals From the Coal Gangue Under the Impact of Site Ordovician Limestone Karst Water From Closed Shandong Coal Mines, North China. Energ. Fuel. 33, 10016-10028 (2019).

4. Chen, A. et al. Well Water Contaminated by Acidic Mine Water From the Dabaoshan Mine, South China: Chemistry and Toxicity. Chemosphere. 70, 248-255 (2007).

5. Liu, P., Gao, Y., Shang, M. \& Yi, X. Predicting Water Level Rises and their Effects On Surrounding Karst Water in an Abandoned Mine in Shandong, China. Environ. Earth Sci. 79, $51(2020)$.

6. Skousen, J. G., Ziemkiewicz, P. F. \& McDonald, L. M. Acid Mine Drainage Formation, Control and Treatment: Approaches and Strategies. The Extractive Industries and Society. 6, 241-249 (2019).

7. Herlihy, A. T., Kaufmann, P. R., Mitch, M. E. \& Brown, D. D. Regional Estimates of Acid Mine Drainage Impact On Streams in the Mid-Atlantic and Southeastern United States. Water, Air, and Soil Pollution. 50, 91-107 (1990).

8. Masindi, V., Chatzisymeon, E., Kortidis, I. \& Foteinis, S. Assessing the Sustainability of Acid Mine Drainage (AMD) Treatment in South Africa. Sci. Total Environ. 635, 793-802 (2018). 9. Masindi, V., Gitari, M. W., Tutu, H. \& DeBeer, M. Efficiency of Ball Milled South African 
Bentonite Clay for Remediation of Acid Mine Drainage. Journal of Water Process Engineering. 8, 227-240 (2015).

10. Galhardi, J. A. \& Bonotto, D. M. Hydrogeochemical Features of Surface Water and Groundwater Contaminated with Acid Mine Drainage (AMD) in Coal Mining Areas: A Case Study in Southern Brazil. Environ. Sci. Pollut. R. 23, 18911-18927 (2016).

11. Huisamen, A. \& Wolkersdorfer, C. Modelling the Hydrogeochemical Evolution of Mine Water in a Decommissioned Opencast Coal Mine. Int. J. Coal Geol. 164, 3-12 (2016).

12. Ward, C. R. Analysis and Significance of Mineral Matter in Coal Seams. Int. J. Coal Geol. 50, 135-168 (2002).

13. Nakagawa, H., Namba, A., Böhlmann, M. \& Miura, K. Hydrothermal Dewatering of Brown Coal and Catalytic Hydrothermal Gasification of the Organic Compounds Dissolving in the Water Using a Novel Ni/carbon Catalyst. Fuel. 83, 719-725 (2004).

14. Yu, J., Tahmasebi, A., Han, Y., Yin, F. \& Li, X. A Review On Water in Low Rank Coals: The Existence, Interaction with Coal Structure and Effects On Coal Utilization. Fuel Process. Technol. 106, 9-20 (2013).

15. Zubrik, A. et al. Distribution of Inorganic and Organic Substances in the Hydrocyclone Separated Slovak Sub-Bituminous Coal. Fuel. 89, 2126-2132 (2010).

16. Yang, Y. et al. Study Governing the Impact of Long-Term Water Immersion on Coal Spontaneous Ignition. Arabian Journal for Science and Engineering. 42, 1359-1369 (2017).

17. Murata, S., Hosokawa, M., Kidena, K. \& Nomura, M. Analysis of Oxygen-Functional Groups in Brown Coals. Fuel Process. Technol. 67, 231-243 (2000).

18. Ogunsola, O. I. Thermal Upgrading Effect On Oxygen Distribution in Lignite. Fuel Process. Technol. 34, 73-81 (1993).

19. Sakaguchi, M., Laursen, K., Nakagawa, H. \& Miura, K. Hydrothermal Upgrading of Loy Yang Brown Coal — Effect of Upgrading Conditions On the Characteristics of the Products. Fuel Process. Technol. 89, 391-396 (2008).

20. Lin, H., Li, G., Dong, Y. \& Li, J. Effect of pH On the Release of Heavy Metals From Stone Coal Waste Rocks. Int. J. Miner. Process. 165, 1-7 (2017).

21. Nor Shahirah, M. N., Abdullah, S., Gimbun, J., Ng, Y. H. \& Cheng, C. K. A Study On the Kinetics of Syngas Production From Glycerol Over Alumina-Supported Samarium-Nickel Catalyst. Int. J. Hydrogen Energ. 41, 10568-10577 (2016).

22. Chuncai, Z. et al. Mobility Behavior and Environmental Implications of Trace Elements Associated with Coal Gangue: A Case Study at the Huainan Coalfield in China. Chemosphere. 95, 193-199 (2014).

23. Álvarez-Valero, A. M., Sáez, R., Pérez-López, R., Delgado, J. \& Nieto, J. M. Evaluation of Heavy Metal Bio-Availability From Almagrera Pyrite-Rich Tailings Dam (Iberian Pyrite Belt, SW Spain) Based On a Sequential Extraction Procedure. J. Geochem. Explor. 102, 87-94 (2009). 24. Cappuyns, V., Alian, V., Vassilieva, E. \& Swennen, R. PH Dependent Leaching Behavior of $\mathrm{Zn}, \mathrm{Cd}, \mathrm{Pb}, \mathrm{Cu}$ and as from Mining Wastes and Slags: Kinetics and Mineralogical Control. Waste and Biomass Valorization. 5, 355-368 (2014).

25. Cai Changfeng, Sun Jing Luo Feixiang. et al. Effects of treatment efficiency of AMD through the PRB based on different structure of MFC Journal of China Coal Society. 41, 13011308 (2016).

26. Pan, J. et al. Recovery of Rare Earth Elements From Coal Fly Ash by Integrated Physical 
Separation and Acid Leaching. Chemosphere. 248, 126112 (2020).

27. Zhang, W., Noble, A., Yang, X. \& Honaker, R. Lithium Leaching Recovery and Mechanisms From Density Fractions of an Illinois Basin Bituminous Coal. Fuel. 268, 117319 (2020).

28. Carroll, S. A., McNab, W. W., Dai, Z. \& Torres, S. C. Reactivity of Mount Simon Sandstone and the Eau Claire Shale Under $\mathrm{CO}_{2}$ Storage Conditions. Environ. Sci. Technol. 47, 252-261 (2012).

29. Finkelman, R. B., Dai, S. \& French, D. The Importance of Minerals in Coal as the Hosts of Chemical Elements: A Review. Int. J. Coal Geol. 212, 103251 (2019).

30. Fu, T., Wu, Y., Ou, L., Yang, G. \& Liang, T. Effects of Thin Covers On the Release of Coal Gangue Contaminants. Energy procedia. 16, 327-333 (2012).

31. Fabiańska, M. J. \& Kurkiewicz, S. Biomarkers, Aromatic Hydrocarbons and Polar Compounds in the Neogene Lignites and Gangue Sediments of the Konin and Turoszów Brown Coal Basins (Poland). Int. J. Coal Geol. 107, 24-44 (2013).

32. Chuncai, Z. et al. Mobility Behavior and Environmental Implications of Trace Elements Associated with Coal Gangue: A Case Study at the Huainan Coalfield in China. Chemosphere. 95, 193-199 (2014).

33. Equeenuddin, S. M., Tripathy, S., Sahoo, P. K. \& Panigrahi, M. K. Hydrogeochemical Characteristics of Acid Mine Drainage and Water Pollution at Makum Coalfield, India. J. Geochem. Explor. 105, 75-82 (2010).

34. Liu, C., Tang, C., Shi, B. \& Suo, W. Automatic Quantification of Crack Patterns by Image Processing. Comput. Geosci.-UK. 57, 77-80 (2013).

35. Liu, C., Shi, B., Zhou, J. \& Tang, C. Quantification and Characterization of Microporosity by Image Processing, Geometric Measurement and Statistical Methods: Application On SEM Images of Clay Materials. Appl. Clay Sci. 54, 97-106 (2011). 
Figures

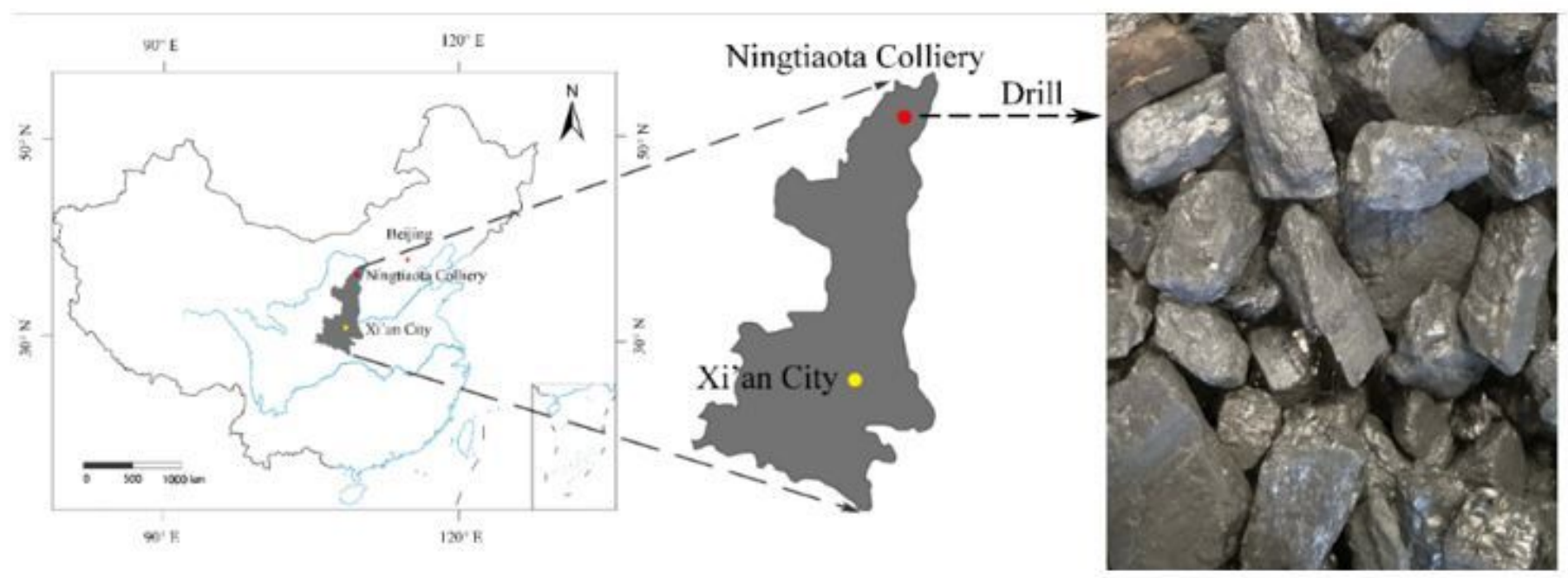

Figure 1

Sampling site of raw coal. 


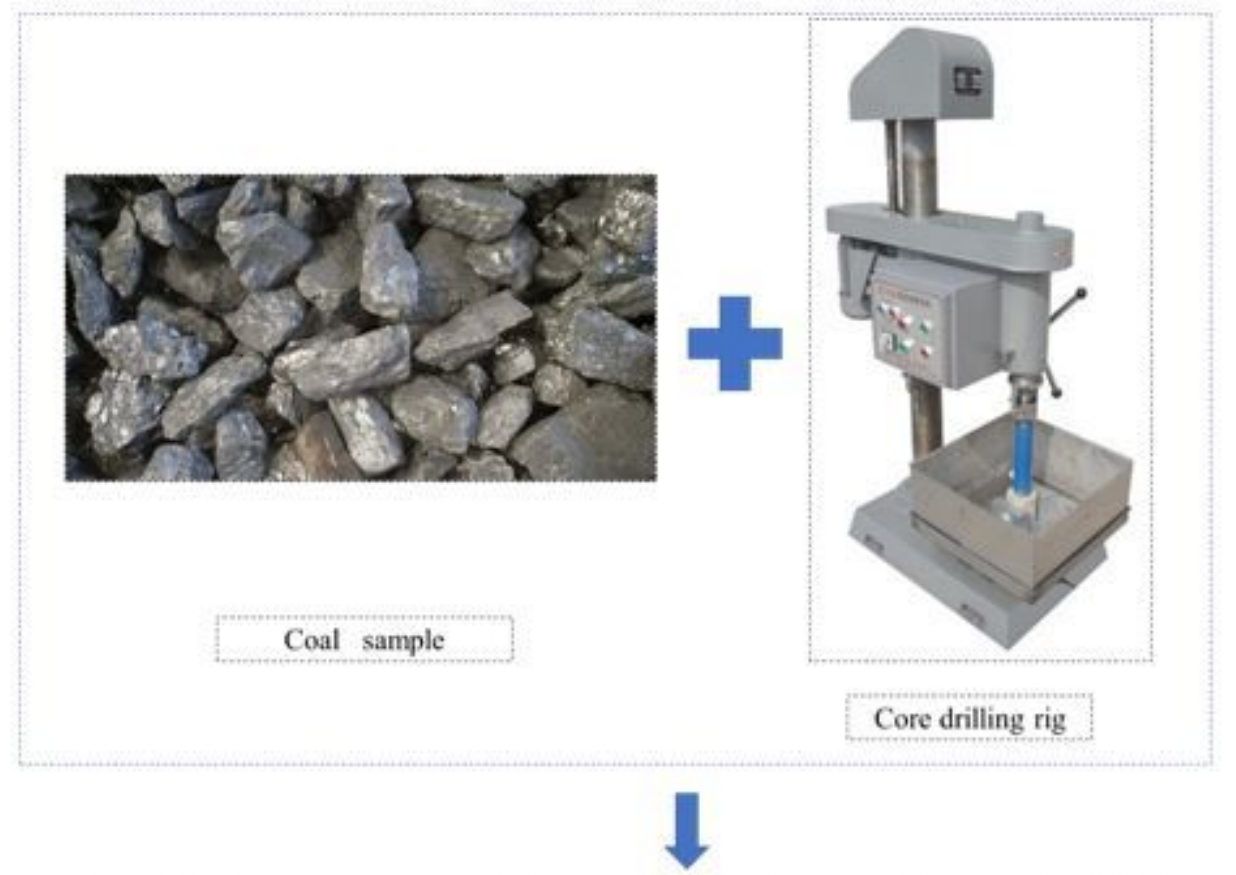

The drilled coal core is then cut and polished at both ends and leveled until the height is $100 \mathrm{~mm}$.

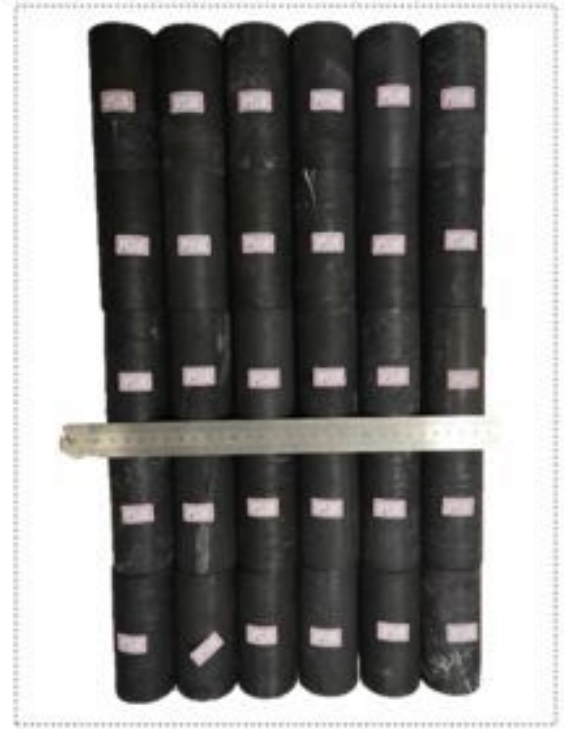

Standard coal sample

Figure 2

Illustration of the coal sample preparation processs. 

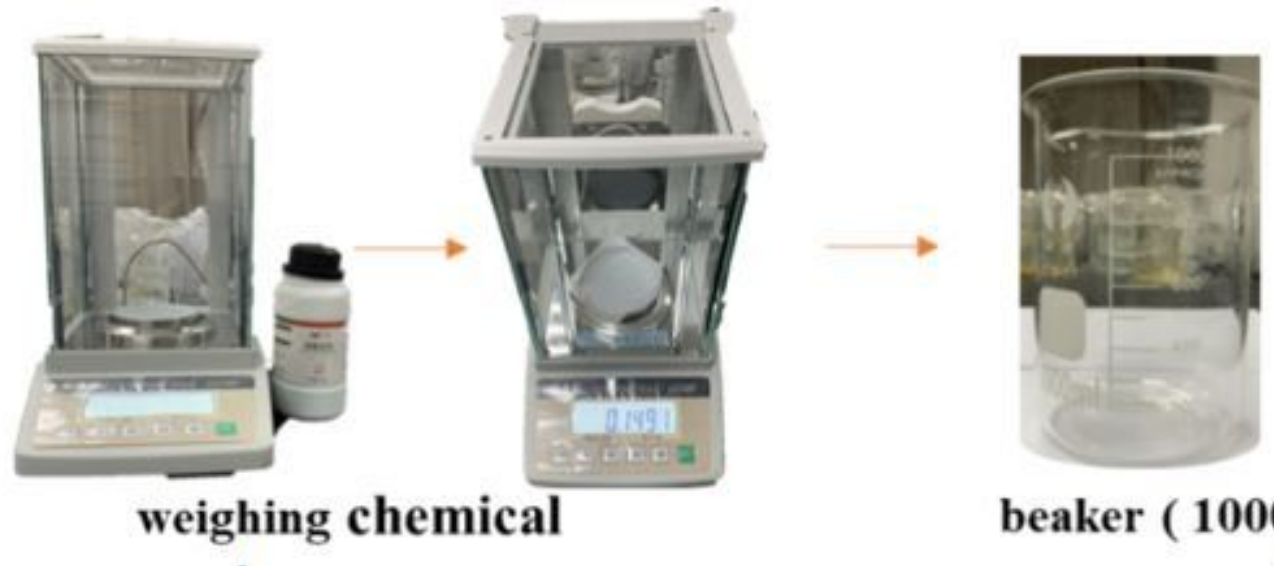

\section{beaker $(1000 \mathrm{ml})$}
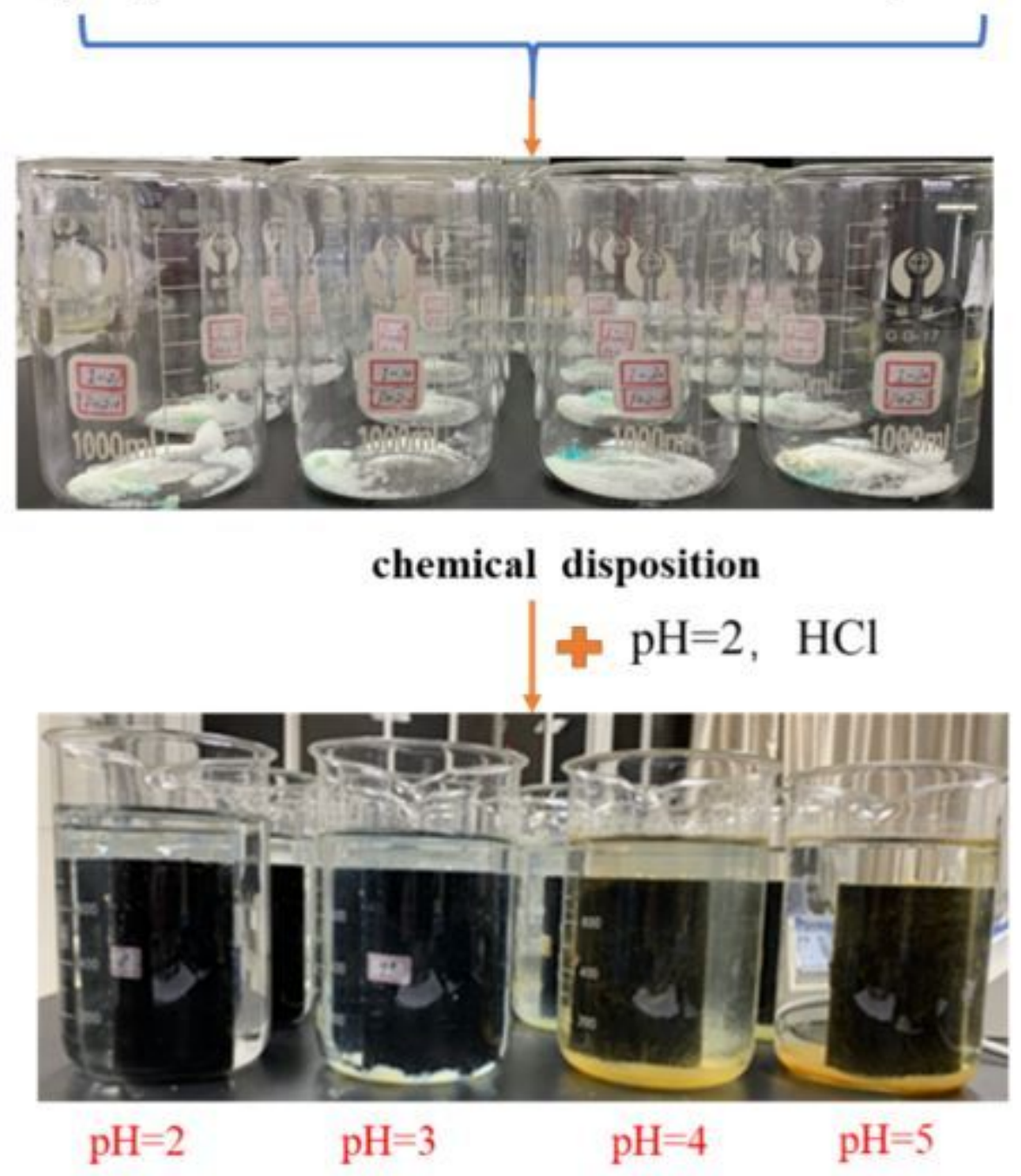

Figure 3

Illustrations of the acid mine drainage preparation and coal samples immersion. 


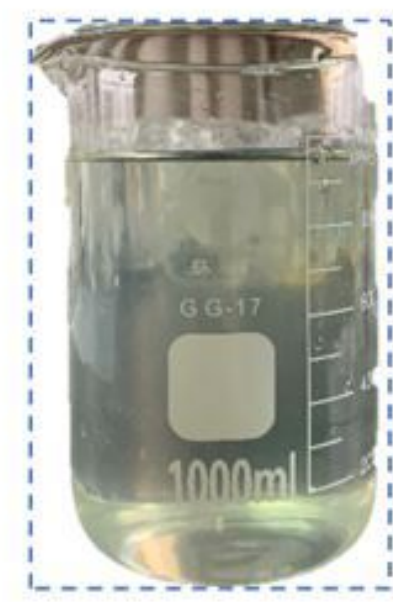

Acid mine water

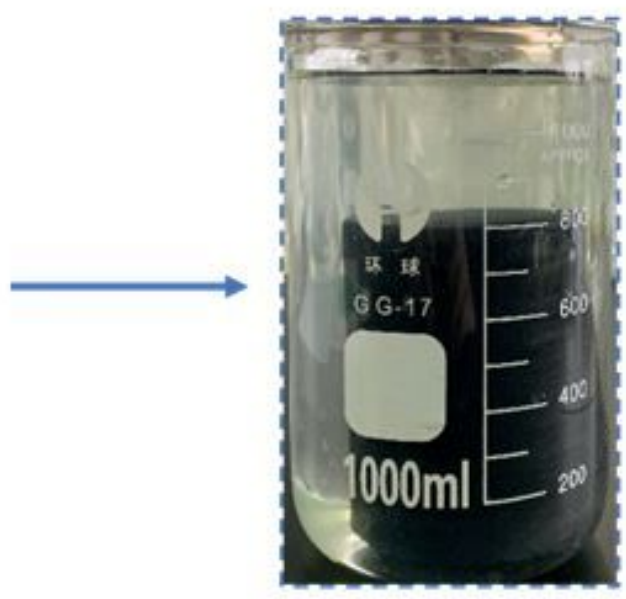

Immersed coal sample

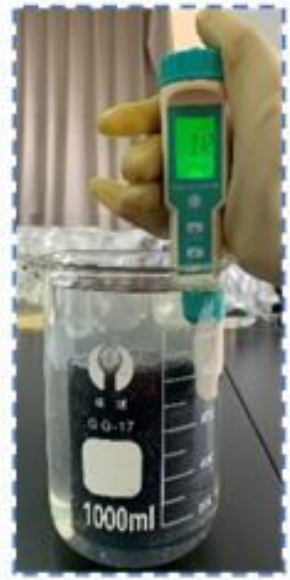

Immersed 10 hours

\section{Figure 4}

Diagram showing the main components of the acid mine drainage coal immersion test.

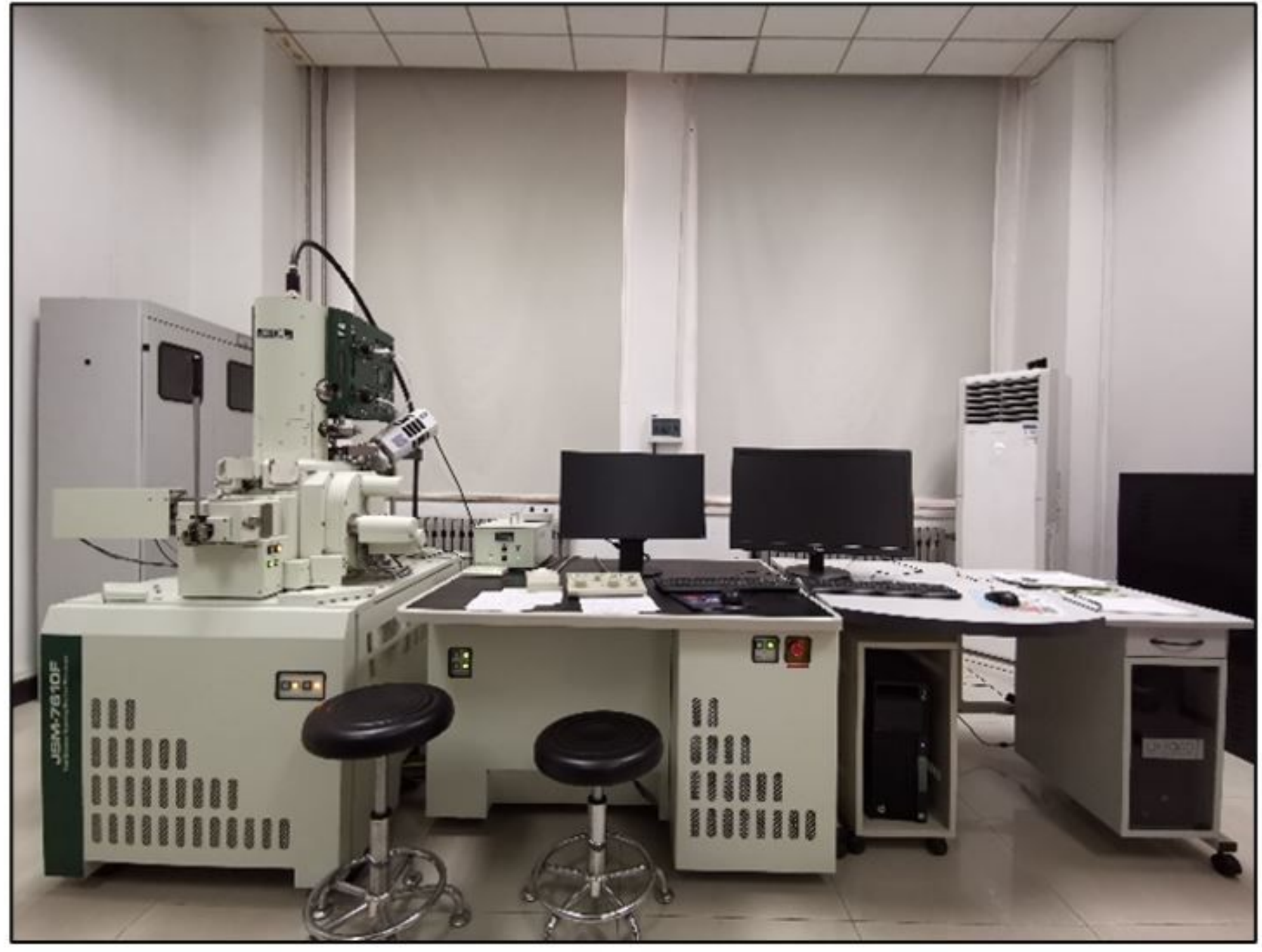


Figure 5

Scanning electron microscopy

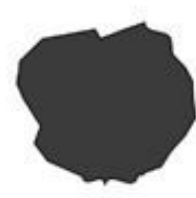

Coal

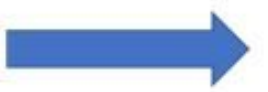

Bake at $60^{\circ} \mathrm{C}$ for $48 \mathrm{~h}$

conature contro
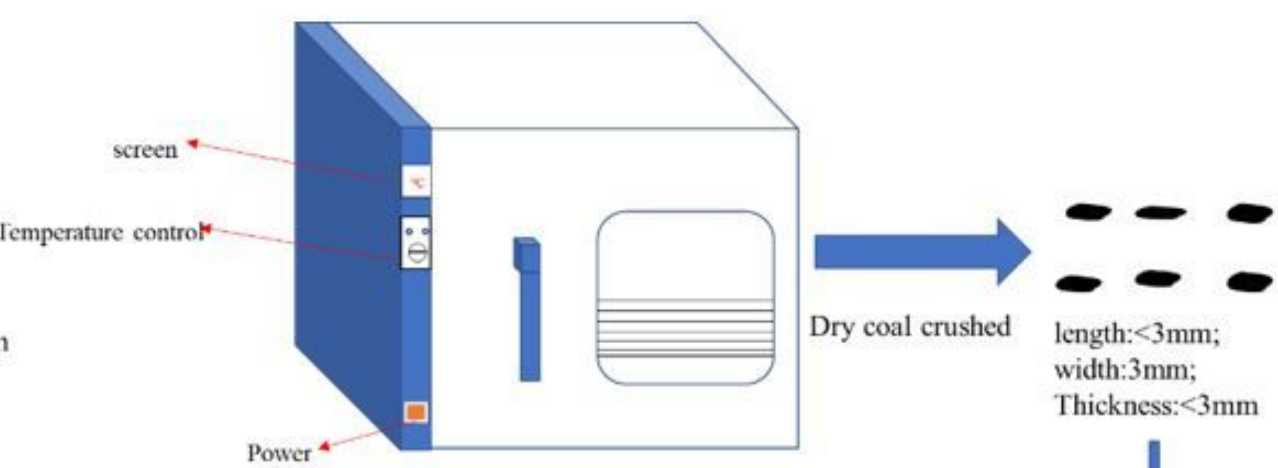

Dry coal crushed

length: $<3 \mathrm{~mm}$; width: $3 \mathrm{~mm}$;

Thickness: $<3 \mathrm{~mm}$

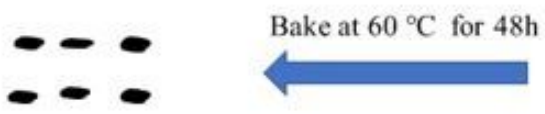

micro slice for SEM test
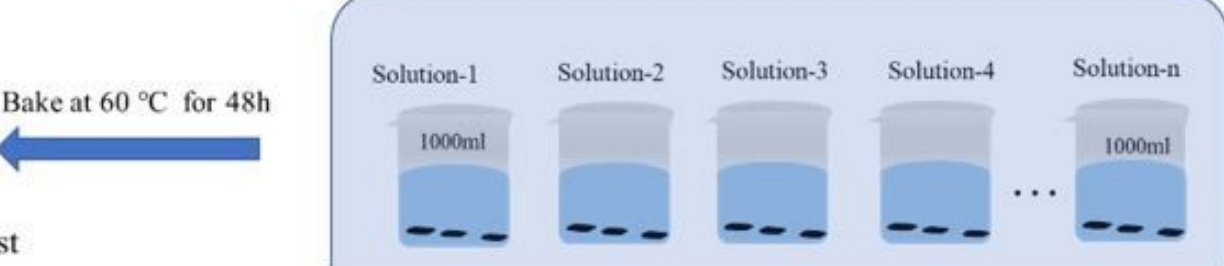

Immersed acid mine water

Figure 6

Scanning electron microscope analysis process . 


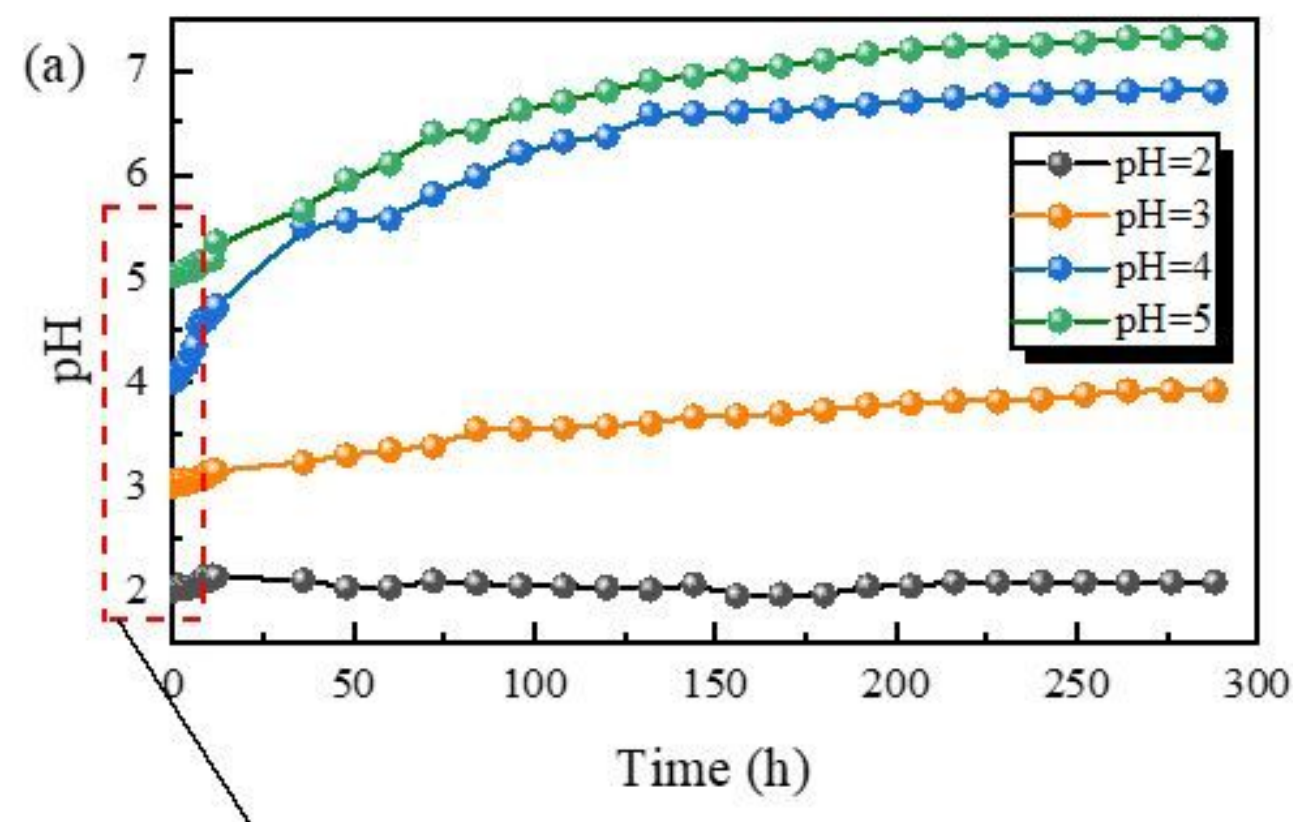

(b)
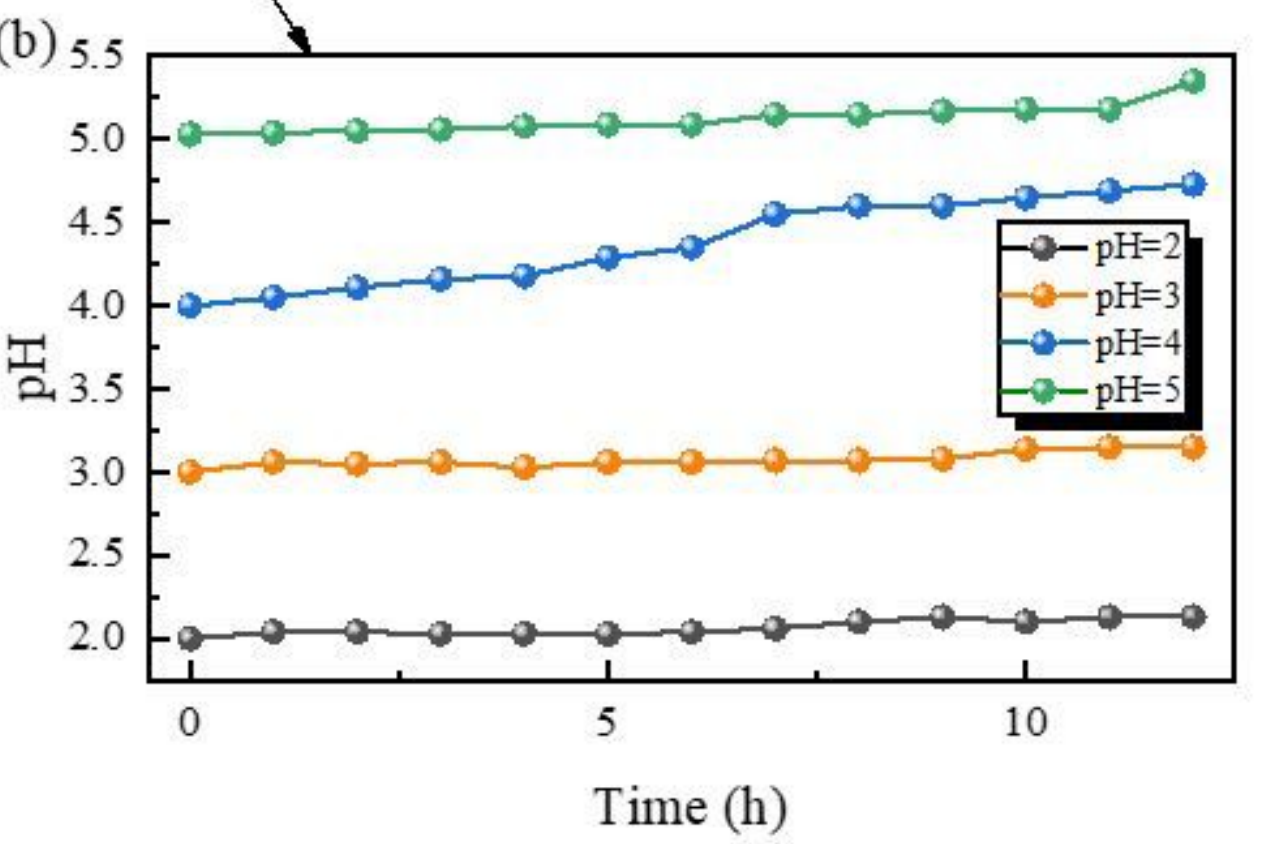

Figure 7

$\mathrm{pH}$ changes in immersion test solutions with initial $\mathrm{pH}$ values of $2,3,4$, and 5 for (a) $300 \mathrm{~h}$ immersion duration and (b) $12 \mathrm{~h}$ immersion.. 


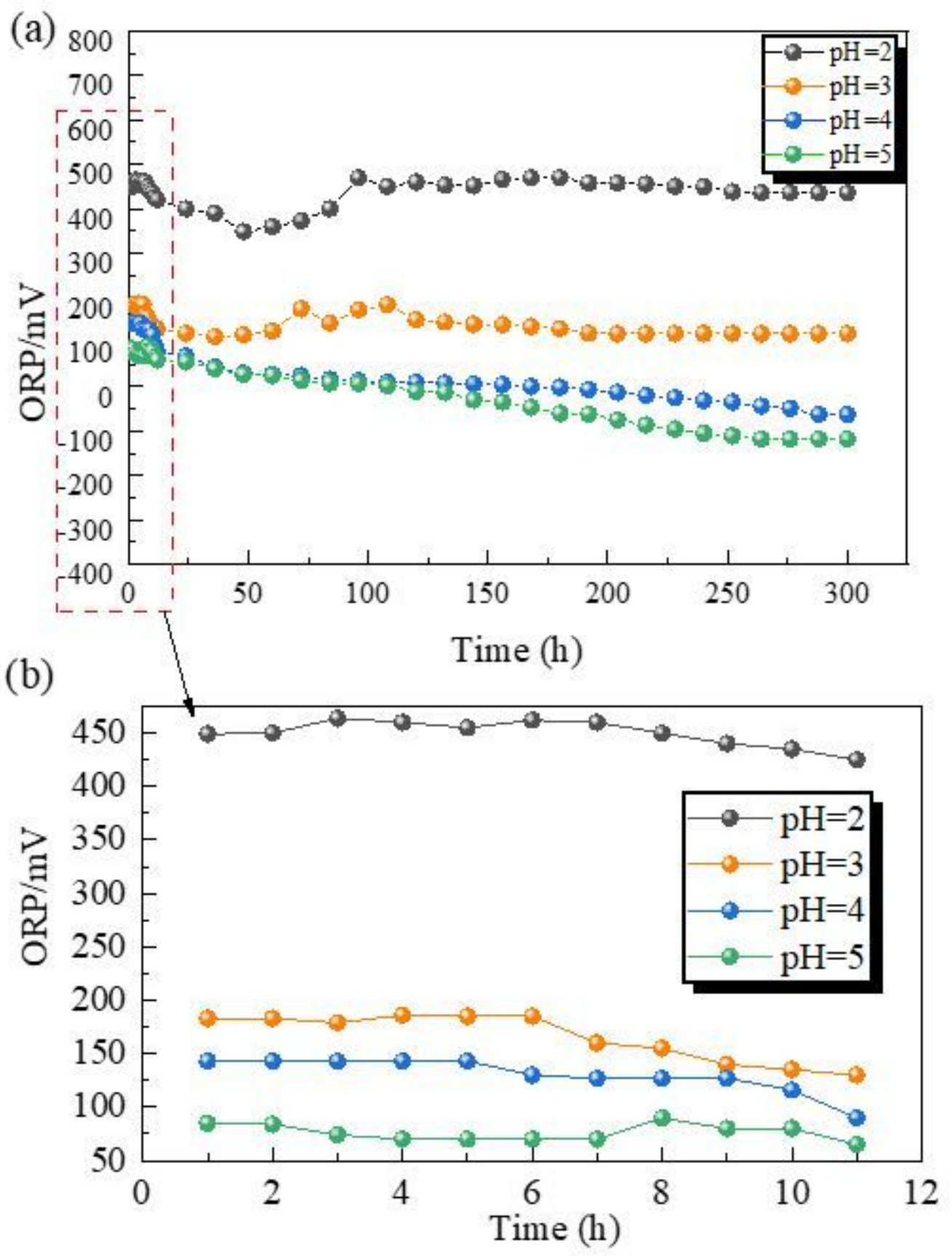

Figure 8

Plot showing changes in ORP values for acidic solutions after coal immersion for (a) $300 \mathrm{~h}$ and (b) $12 \mathrm{~h}$. 


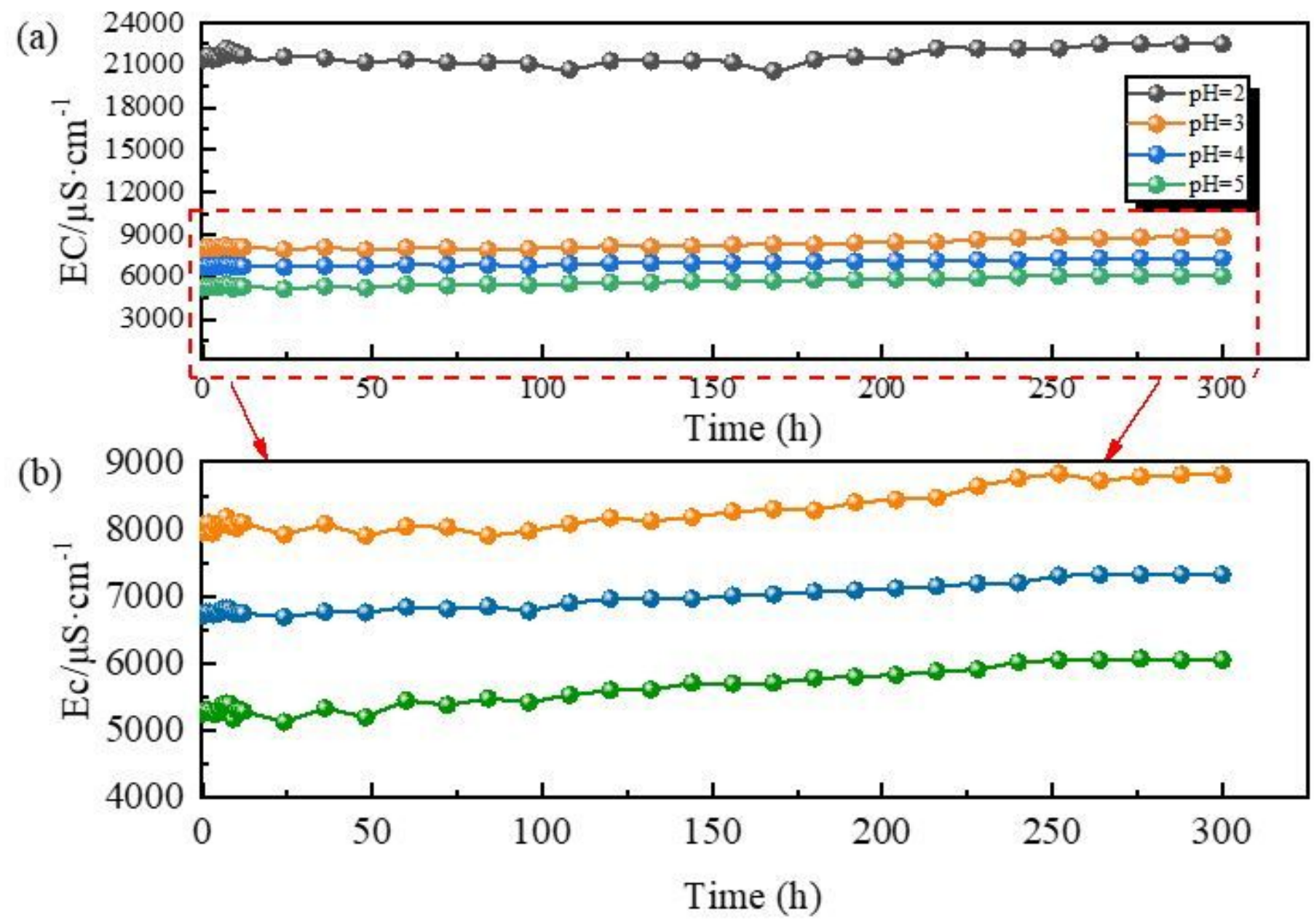

Figure 9

Changes in electrical conductivity values of acidic solutions ( $\mathrm{pH}$ values of $2-5$ ) for (a) the test duration of $300 \mathrm{~h}$ and $(\mathrm{b})$ relative to the original EC value. 


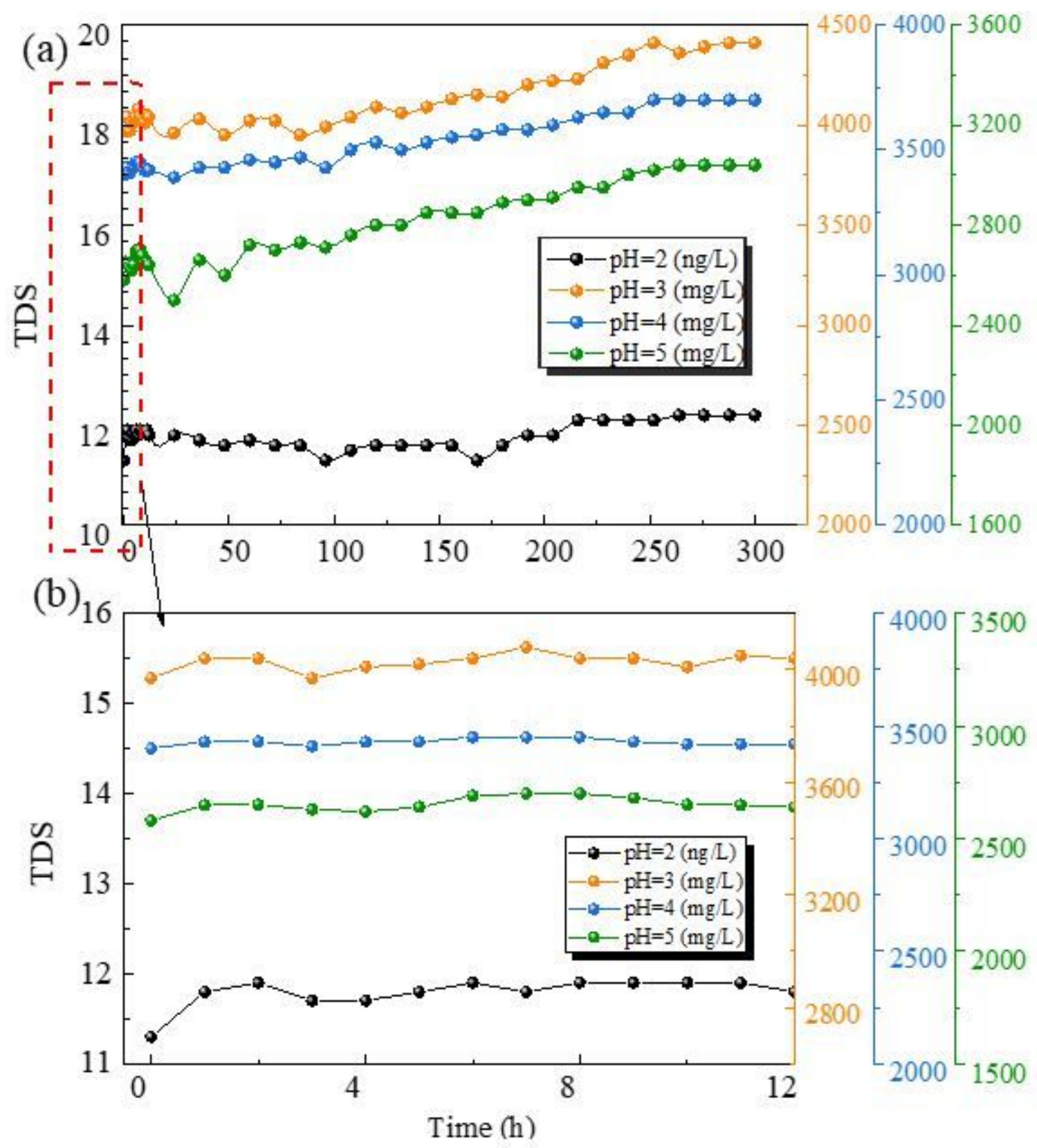

Figure 10

TDS changes in acidic solutions with initial pH values of $2,3,4$, and 5 for (a) $300 \mathrm{~h}$ and (b) the initial $12 \mathrm{~h}$ 

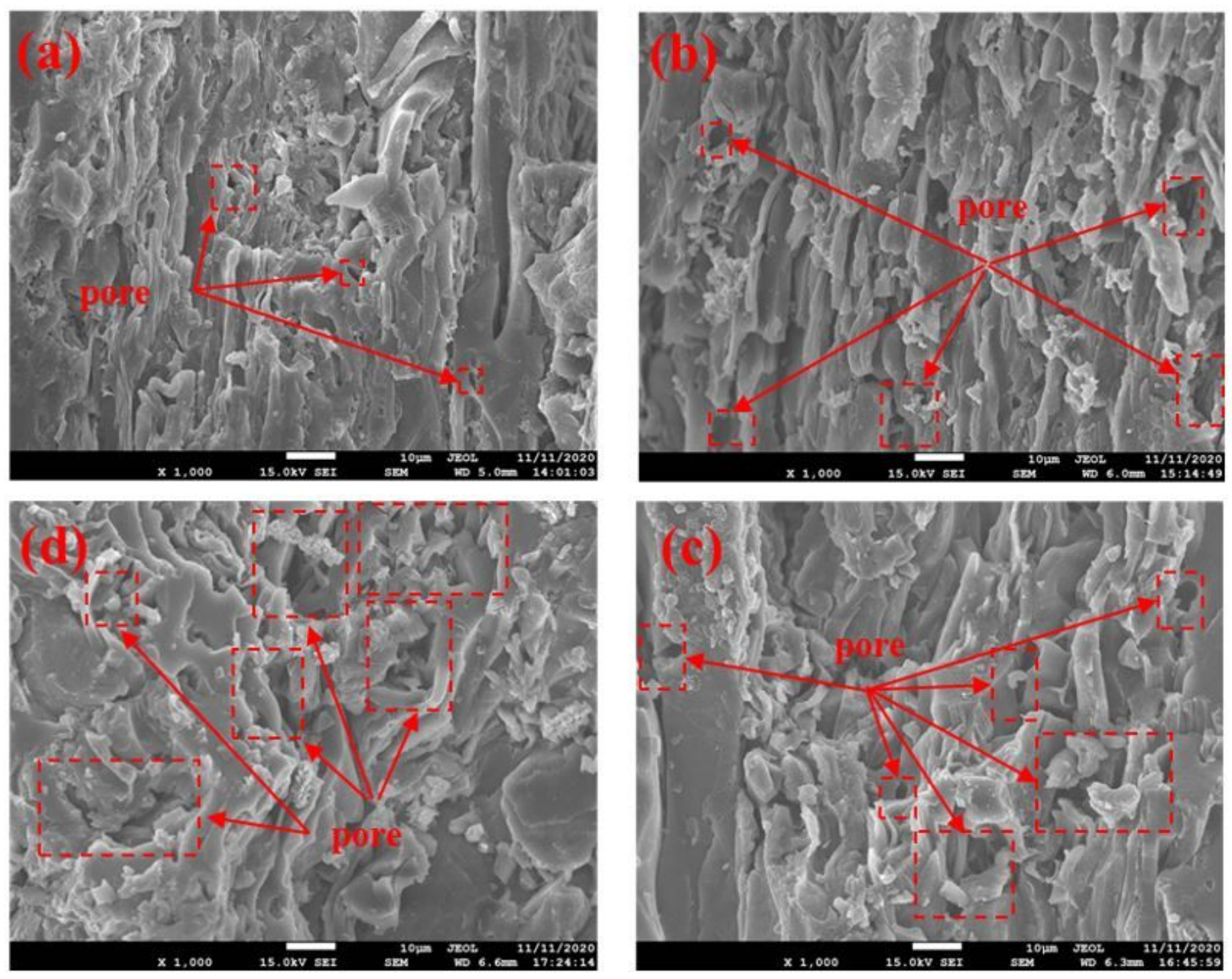

Figure 11

Morphology of coal samples immersed in acidic solutions including (a) $\mathrm{pH}-5$, (b) $\mathrm{pH}-4$, (c) $\mathrm{pH}-3$, and (d) $\mathrm{pH}-2$. 

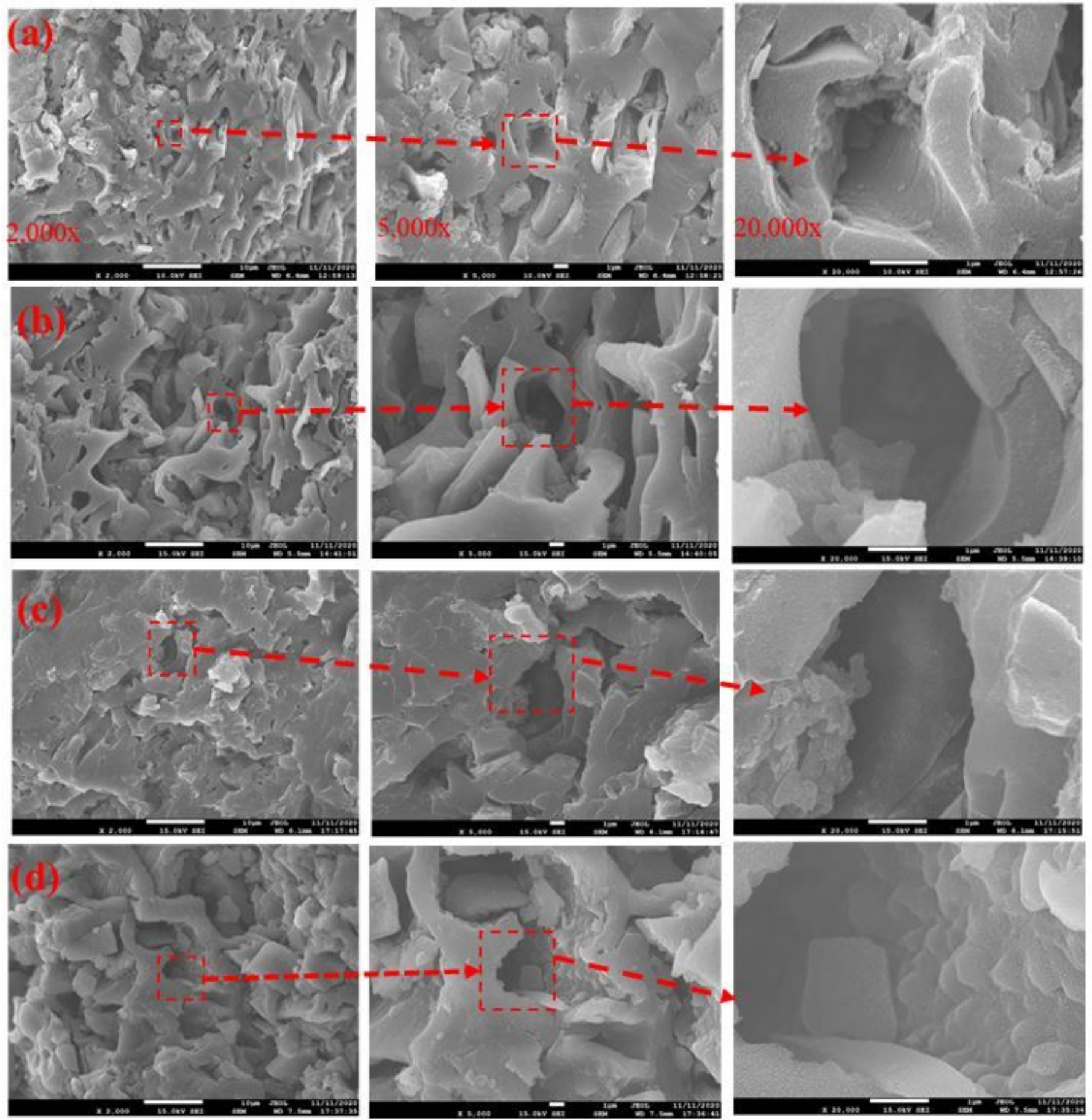

Figure 12

Morphology of pores in coal exposed to acidic solutions including (a) $\mathrm{pH}-5$, (b) $\mathrm{pH}-4$, (c) $\mathrm{pH}-3$, and (d) $\mathrm{pH}-$ 2 , The magnification from left to right are: 2,000x, 5,000x, and 20,000x . 

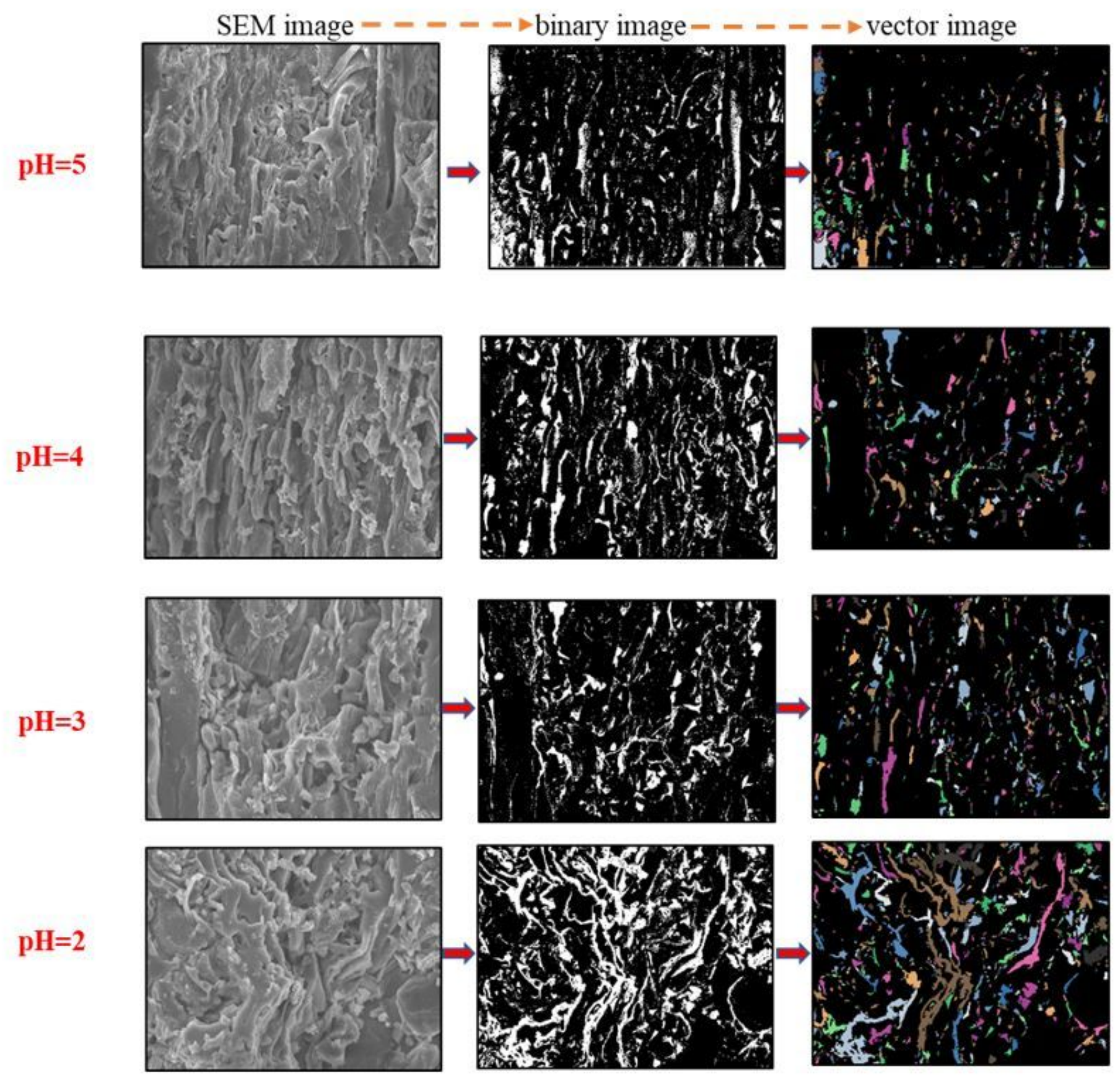

Figure 13

Illustration of the identification and analysis process of coal pores using the PCAS software at 1,000x magnification . 

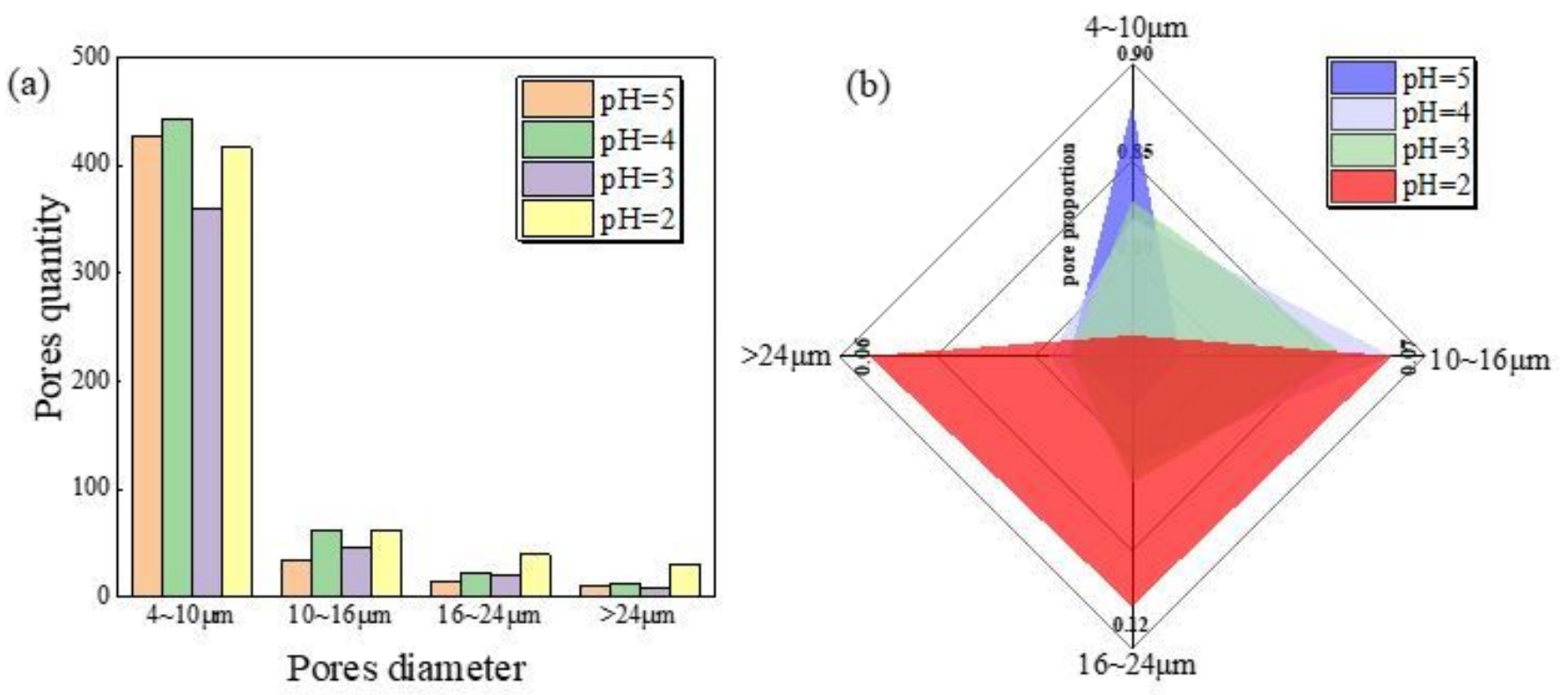

\section{Figure 14}

Quantitative analysis coal pore characteristics including the (a) distribution of pore throat diameters and (b) proportions of various pore diameters.

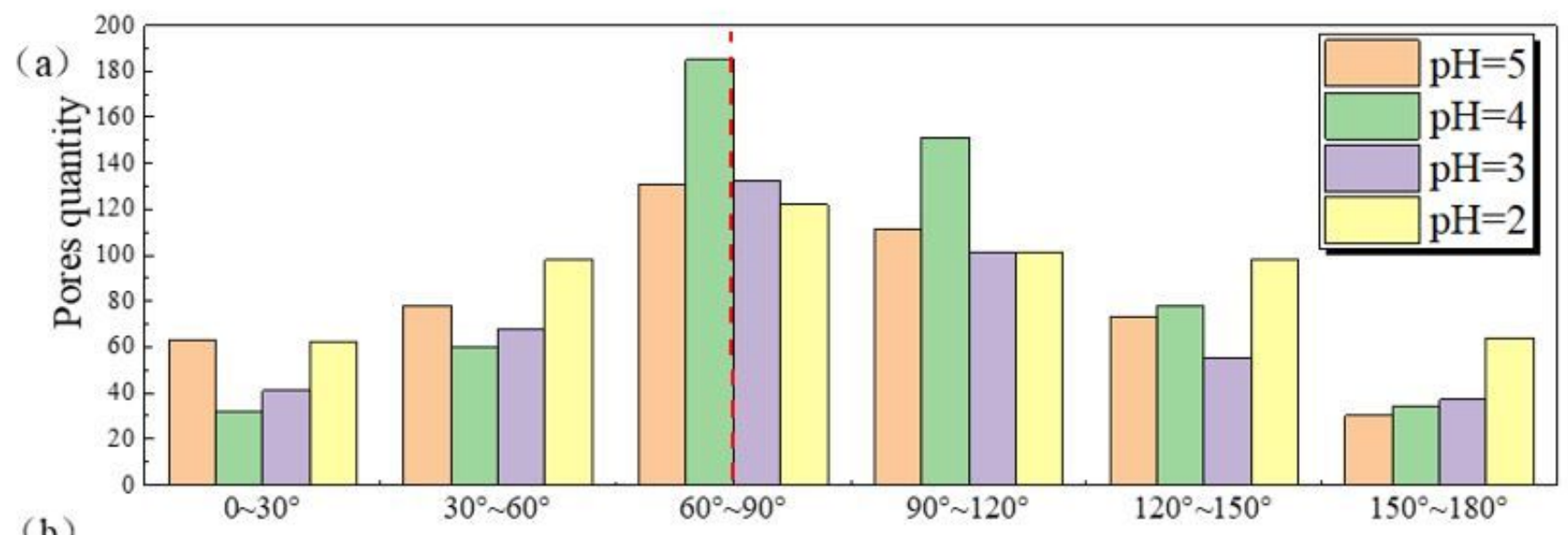

(b)

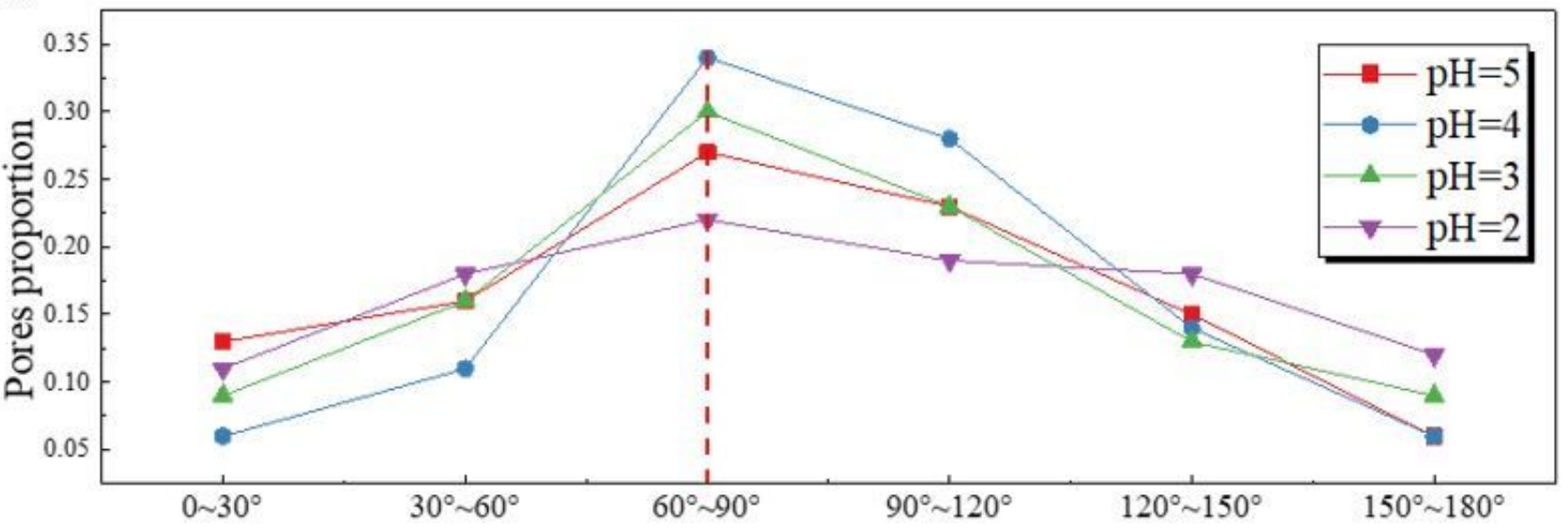

Direaction 
Figure 15

Orientation of coal pores associated with different acidic solutions including the (a) pore orientation distribution and (b) proportion of pores in different orientation ranges.
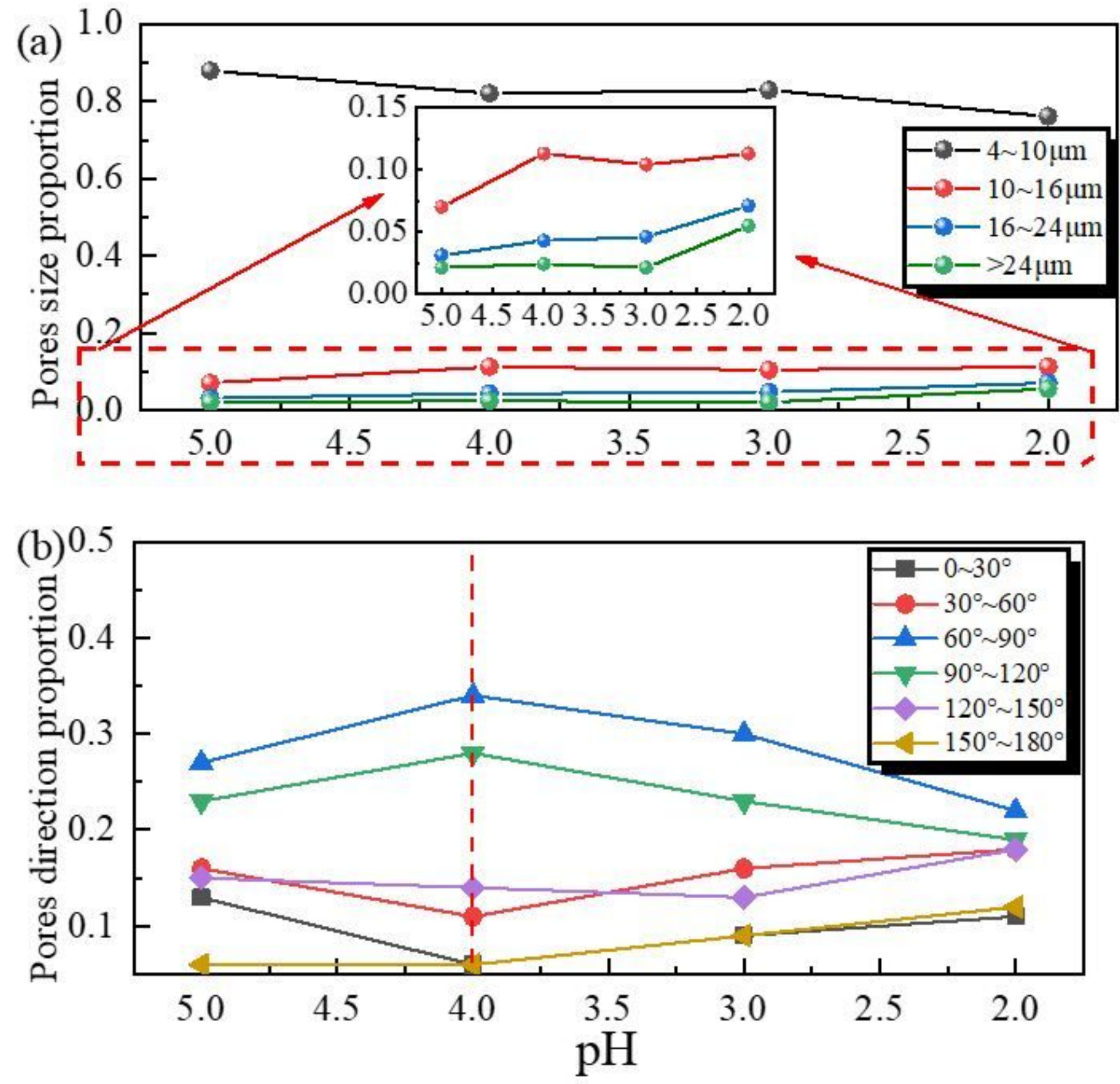

Figure 16

Effect of acidic solutions with different $\mathrm{pH}$ on structural parameters of coal pores including the relationship between (a) solution $\mathrm{pH}$ and pore size and (b) solution $\mathrm{pH}$ and pore direction . 